\title{
Putting Personal Knowledge Management under the Macroscope of Informing Science
}

\author{
Ulrich Schmitt \\ University of Stellenbosch Business School, South Africa
}

schmitt@knowcations.org

\begin{abstract}
The paper introduces a novel Personal Knowledge Management (PKM) concept and prototype system. The system's objective is to aid life-long-learning, resourcefulness, creativity, and teamwork of individuals throughout their academic and professional life and as contributors and beneficiaries of organizational and societal performance. Such a scope offers appealing and viable opportunities for stakeholders in the educational, professional, and developmental context.

To further validate the underlying PKM application design, the systems thinking techniques of the transdiscipline of Informing Science (IS) are employed. By applying Cohen's IS-Framework, Leavitt's Diamond Model, the IS-Meta Approach, and Gill's and Murphy's Three Dimensions of Design Task Complexity, the more specific KM models and methodologies central to the PKMS concept are aligned, introduced, and visualized. The extent of this introduction offers an essential overview, which can be deepened and broadened by using the cited URL and DOI links pointing to the available resources of the author's prior publications.

The paper emphasizes the differences of the proposed meme-based PKM System compared to its traditional organizational document-centric counterparts as well as its inherent complementing synergies. As a result, it shows how the system is closing in on Vannevar Bush's still unfulfilled vison of the 'Memex', an as-close-as-it-gets imaginary ancestor celebrating its $70^{\text {th }}$ anniversary as an inspiring idea never realized. It also addresses the scenario recently put forward by Levy which foresees a decentralizing revolution of knowledge management that gives more power and autonomy to individuals and self-organized groups. Accordingly, it also touches on the PKM potential in terms of Kuhn's Scientific Revolutions and Disruptive Innovations.
\end{abstract}

Keywords: Personal Knowledge Management (PKM), Organizational Knowledge Management (OKM), PKM for Development (PKM4D), Informing Science Framework, Human Capital, Capacity Development, Lifelong learning, Memes, Memex, Knowcations, Disruptive Innovations, Kuhn's Scientific Revolutions.

Material published as part of this publication, either on-line or in print, is copyrighted by the Informing Science Institute. Permission to make digital or paper copy of part or all of these works for personal or classroom use is granted without fee provided that the copies are not made or distributed for profit or commercial advantage AND that copies 1) bear this notice in full and 2) give the full citation on the first page. It is permissible to abstract these works so long as credit is given. To copy in all other cases or to republish or to post on a server or to redistribute to lists requires specific permission and payment of a fee. Contact Publisher@,InformingScience.org to request redistribution permission.

Editor: T. Grandon Gill

Submitted January 1, 2015; Revised March 19, 2015; Accepted April 17, 2015 


\section{The Informing Science Framework as a Macroscope}

After praising the merit of the microscope and the telescope for advancing scientific knowledge, De Rosnay presented the notion of the macroscope, "a symbolic instrument made of a number of methods and techniques borrowed from very different disciplines" as a tool for the direct observation of complexity and complex systems which should be looked at as a whole, rather than be taken apart into their constituents (De Rosnay, 1979, p. 6).

The systems thinking techniques (selected terms being introduced for the first time are shown in italics indicating their inclusion in the paper's glossary) applied as a macroscope, in the context of this paper, are part and parcel of the transdiscipline of Informing Science (IS) tasked to "provide their clientele with information in a form, format, and schedule that maximizes its effectiveness" (Cohen, 1999, p. 215). The definition is supported by communication process models, by a 'meta-approach' to modelling, as well as by Leavitt's Diamond Model which provides an integrated approach to change (Cohen, 1999; Leavitt, 1965). The resulting IS-Framework (Figure 1) visualizes "the contextual environment of the informer, information transmission and receiving media, and receiver of information" and "explicitly acknowledges that they exist within complex environments that greatly impact them. For example, the entity being informed is influenced by its own psychological and physiological fragilities and operates within task requirements (and anticipations), all of which exist within and are influenced by environmental context" (Cohen, 2009, p. 8).

The system to be scrutinized is a novel Personal Knowledge Management (PKM) Concept (supported by a prototype system named 'Knowcations') which has been used personally for career support as a management consultant, scholar, professor, and academic manager. Recent advances in development and hosting platforms have now provided a viable opportunity for innovation and its conversion into an application serving a wider audience and multiple platforms.

Over the last 2.5 years of continued system development, a range of papers has been published addressing multiple aspects of what can be considered as a 'Next Knowledge Management System Generation' approach (Schmitt, 2015e). This paper summarizes and references essential components covered and adds new design elements and/or representations to meet the holistic perspective of the macroscope in order to validate the PKM System (PKMS) against the Informing Science Framework.

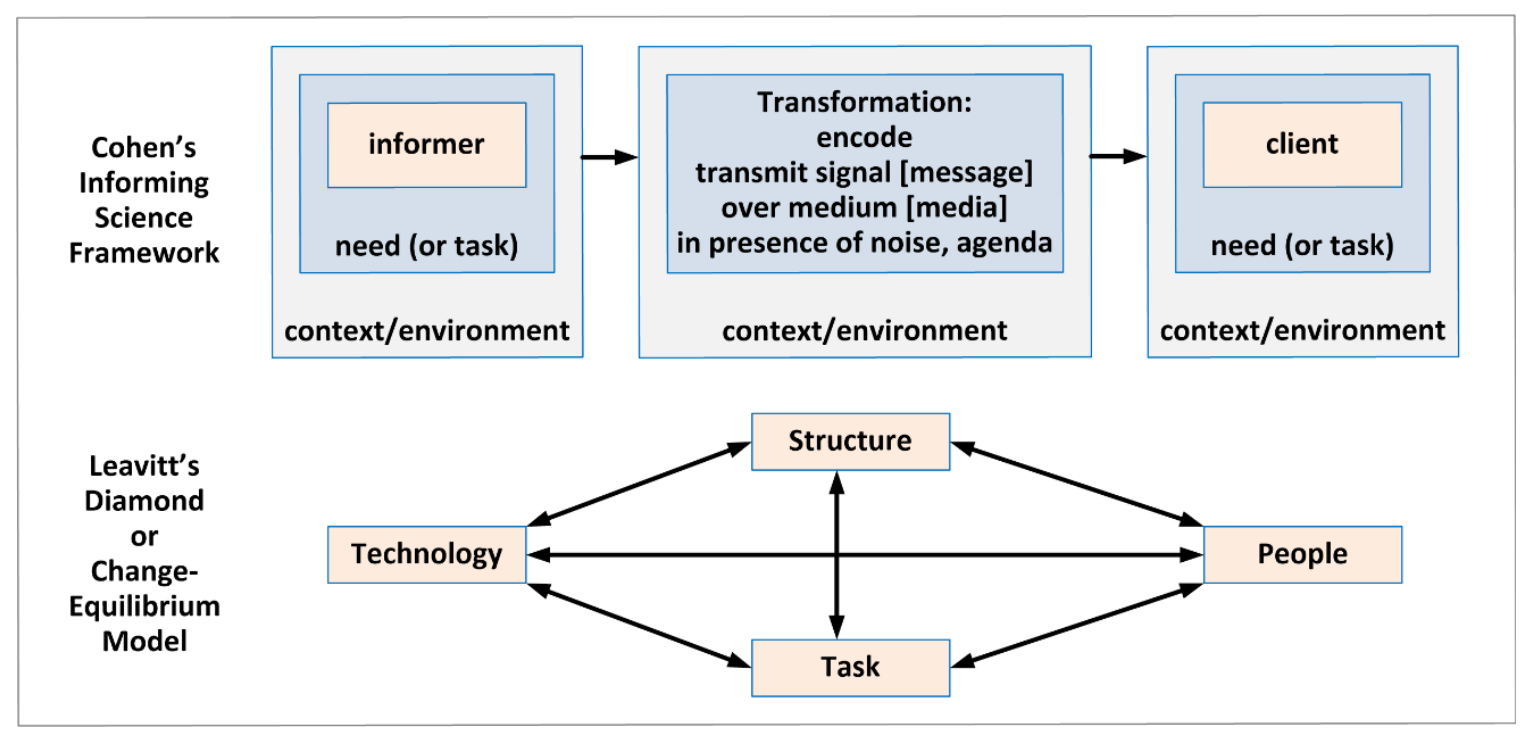

Figure 1: Leavitt's Diamond and the Informing Science Framework (Cohen, 2009) 


\section{Leavitt's Diamond vs. KM as an Enduring Discipline}

Based on a comprehensive analysis of the evolving discourse on Knowledge Management (KM), K. Grant (2011, p. 117) considers KM as "an enduring management activity" with "no decline apparent" and provides "bibliometric evidence that there has been a sustained interest in KM that is quite unlike that of other popular management themes over the last 30 years". He also identifies "a potential conflict between the interests of practitioners and researchers", "inconsistent views", and "raises some questions about the relevance of some of the research being carried out".

Grant's assessment confirms Heisig's view (2009, pp. 4, 10) that KM "has entered into a new phase where consolidation and harmonization of concepts is required." Heisig arrived at his conclusion by comparing 119 KM Frameworks from around the world and their respective "successcritical context factors" which resulted in a total of 424 terms made use of categorized into four main clusters: human factors (culture, people and leadership), organizational aspects (structures and processes), information technology, as well as a management processes (strategy and control). He further observed, "A broad consent prevails over the fact that a one-sided implementation of only one of these factors does not correspond to KM as a holistic effort. The task of KM is to arrange these factors in such a manner that the KM activities can be achieved as smoothly as possible."

\begin{tabular}{|c|c|c|c|c|}
\hline 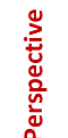 & $\begin{array}{l}\text { 'Real World' Ideosphere (I) } \\
\text { (Intelligence \& Extelligence) }\end{array}$ & $\begin{array}{c}\text { Representational Model (R) } \\
\text { (Organizational \& Structural) }\end{array}$ & $\begin{array}{l}\text { People Spaces \& Tasks (P) } \\
\text { (Managerial \& Operative) }\end{array}$ & $\begin{array}{c}\text { Technology \& Platform (T) } \\
\text { (Technology-as-a-Tool) }\end{array}$ \\
\hline 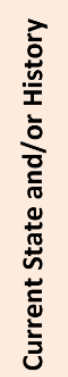 & $\begin{array}{l}\text { - From Information } \\
\text { Scarcity to Abundance } \\
\text { - Wealth of Information } \\
\text { is creating a } \\
\text { Poverty of Attention } \\
\text { - Need of Educational } \\
\text { Interventions for } \\
\text { Autonomous KM } \\
\text { Capacities } \\
\text { - Knowledge Society }\end{array}$ & $\begin{array}{l}\text { Personal (PC) versus Orga- } \\
\text { ganisational Capitals (OC) } \\
\text { - } \sum \text { Intellectual PC \& } \\
\text { Competencies \& Skills } \\
\text { = Human OC, } \\
\text { - } \sum \text { Social PC = } \\
\text { Relationship OC, } \\
\text { - } \sum \text { Emotional PC } \\
\text { = Strategic OC, } \\
\text { - } \sum \text { Personal Structural } \\
\text { Intellectual PC Assets } \\
\text { = Structural OC. }\end{array}$ & $\begin{array}{l}\text { Management Phases } \\
\text { - Industrial Revolution } \\
\text { - production \& finance } \\
\text { - } 1920 \\
\text { - Produktivity Growth } \\
\text { - sales \& supply driven } \\
\text { - Technological Progress } \\
\text { - market/demand driven } \\
\text { - } 1970 \\
\text { - Saturation of Markets } \\
\text { - system/customer focus } \\
\text { - Kno00 } \\
\text { - Knowledge Economy } \\
\text { - e-business social media }\end{array}$ & $\begin{array}{l}\text { Technological Innovations } \\
\text { - Learning, Imitation, and } \\
\text { Language } \\
\text { - Writing, Printing, and } \\
\text { Institutional Memory } \\
\text { - Digitization, Information } \\
\text { and Communication } \\
\text { Technology } \\
\text { - Cloud Computing and } \\
\text { Industrial Internet }\end{array}$ \\
\hline & Organizational & Knowledge & Management & Systems (OKMS) \\
\hline 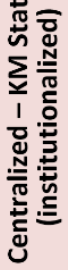 & $\begin{array}{l}\text { Institutional Ownership } \\
\text { (Top-Down Approach) } \\
\text { Characterized by } \\
\text { Prohibitive Restrictions } \\
\text { for individual Users and } \\
\text { Captured Client Audiences } \\
\text { (Seven PKM Barriers) }\end{array}$ & $\begin{array}{l}\text { Document or Entity-centric } \\
\text { Knowledge Bases } \\
\text { With the Shortcomings of } \\
\text { Insulated and incompatible } \\
\text { Silos of Contents controlled } \\
\text { by Large Organizations and } \\
\text { 'Semantic Silos' of Ontologies }\end{array}$ & $\begin{array}{l}\text { Successive KM Generations } \\
\text { each addressing Short- } \\
\text { comings of Predecessors: } \\
\text { IT-driven I.C. Protection G1 } \\
\text { Organizational Learning G2 } \\
\text { Taxonomy Construction G3 }\end{array}$ & $\begin{array}{l}\text { Monolithic Technologies } \\
\text { Characterized by } \\
\text { Large Investment and } \\
\text { Costly Maintenance }\end{array}$ \\
\hline 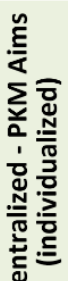 & $\begin{array}{c}\text { Personal Sovereignty } \\
\text { (Grass Roots Approach) } \\
\\
\text { Characterized by } \\
\text { Sustainable Autonomy \& } \\
\text { Creative Conversations } \\
\text { (Five PKM Provisions) } \\
\text { (PKM4D Framework) }\end{array}$ & $\begin{array}{c}\text { Meme-based Repositories } \\
\text { (Biographically Self-Determined) } \\
\text { Characterized by } \\
\text { User-Configured Trails, } \\
\text { Documents, Knowl. Assets } \\
\text { and Globally Shared World } \\
\text { Heritage Site of Memes }\end{array}$ & $\begin{array}{l}\text { - Distributed Autonomous } \\
\text { PKMS Capacities engaged } \\
\text { in Creative Conversations } \\
\text { - Where Personal Devices } \\
\text { facilitate the Emergence } \\
\text { of Distributed Processes } \\
\text { of Collective Extelligence } \\
\text { and Intelligence, which in } \\
\text { turn feed them (Levy 2011) }\end{array}$ & $\begin{array}{l}\text { Individual Affordable } \\
\text { Autonomous Devices } \\
\text { Characterized by } \\
\text { Multiple Platforms } \\
\text { and Cloud Connectivity }\end{array}$ \\
\hline ธั๊ & Personal & Knowledge & Management & Systems (PKMS) \\
\hline
\end{tabular}

Figure 2: Changing Organizational and Personal KM Perspectives (using Leavitt's Diamond) 
Heisig's four clusters and observations endorse one of the IS-pillars, Leavitt's Diamond Model, which also postulates that change may affect four components and, hence, has to be approached from four different perspectives: human factors, structure, technology, managerial, and operative tasks (representing the four points of the diamond in Figure 1). A change affecting any one component will very likely have an impact on the others, and - as a consequence - any change process has to take account of these interdependencies in order to be managed effectively (Leavitt, 1965).

Figure 2 summarizes selected aspects of these four perspectives/components (with human factors represented by intelligence and extelligence) from three interdependent angles (current state and/or history, KM status, and PKM aims) to be further described below.

\section{Technology and Platform As-a-Tool Perspective}

Although civilization can be divided into distinct development phases, the emerging common denominator was and is the ever advancing capacities of individuals to imitate, learn, and innovate. A prior paper argues that the human progress encountered can be attributed to the emergence/invention of four successive communication and information technologies (column $\mathrm{T}$ of Figure 2) which, in turn, have given rise to embodied and embrained, encapsulated and encultured, encoded and organizational, and digitized, networked, and enclouded knowledge and information. Each transitional stage presented emerging constraints which could only be overcome by novel co-evolving social and physical technologies (Beinhocker, 2006; Schmitt, 2014b).

In terms of KM, these developments have resulted in today's monolithic system applications run by large organizations and requiring considerable investments for development and maintenance.

\section{Managerial and Operative Tasks and Space Perspective}

Just a century ago, Frederick W. Taylor, considered to be the father of scientific management, stated, "In our scheme, we do not ask the initiative of our men. We do not want any initiative. All we want of them is to obey the orders we give them, do what we say, and do it quick" (Will, 1997). Since then, the competitive needs have forced enterprises to adjust their operations and management focus: from the production and finance area of the early industrial age to a sales and supply driven approach, followed by an emphasis on markets and demand towards system and customer orientation with a more recent attention on e-business and social media. The effects of the corresponding ever-adapting professional techniques have thoroughly transformed Taylor's hierarchical leadership thinking. "Engagement [of employees] may have been irrelevant in the industrial economy and optional in the knowledge economy, but [in today's creative economy] it's pretty much the whole game now" (Hamel, 2012, p. 79).

$\mathrm{KM}$, in its short history, has already also experienced a number of transformations. A recent paper itemizes $48 \mathrm{KM}$ models, theories, and metaphors applied by the ensuing KM generations (labelled G123 in column P of Figure 2) and considered which - in terms of the 'next generation' PKM concept to be introduced - have passed the test of time (Schmitt, 2015e).

\section{Organizational-Structural (Representational) Perspective}

Hamel reaffirms a widely recognized insight that the most valuable asset in any organization or society is investment in intangible human capital and that the key competitive drivers are knowledge, creativity, and innovation (Schmitt, 2014c). Hence, Gratton (2011, pp. 68, 196-201) advises knowledge workers to attend to and grow their Social, Emotional, and Intellectual Capital in order to "write a personal career script that can bring fulfillment and meaning." Together with the individual competencies, skills, and tool sets (labelled personal structural intellectual capital assets (Wiig, 2011)), these resources - aggregated across a firm's workforce - closely fit the potentially accessible human capital categories of an enterprise (column R of Figure 2). 
"Unfortunately, the language of knowledge management has created an image of organizational knowledge [through the metaphor of an asset] as having an independent existence such that it can be [straightforwardly] stored, retrieved, transmitted, absorbed and replicated. [But], a pragmatic view of knowledge (situated performance) suggests that none of these terms are strictly applicable" (Hanson, 2013, p. 195).

Accordingly, Levy stresses "the growing role of creative conversation in explicating, accumulating and organizing knowledge in the shared memories of knowledge communities" as well as "the need for a personal discipline for collection, filtering and creative connection (among data, among people, and between people and data flows)." KM "on the Web is [also] too collectivized, in fact, balkanized among many competing services, many languages, many ontologies. And the situation is often much worse in big companies and public administrations, whose databases are frequently unable to communicate with each other." "One of the ideals of social knowledge management is clearly its decompartmentalization, exchangeability and commensurability. [...] Let us recall the well-known silos created by the incompatible formats of the 'clouds' controlled by the big companies of the Web or the 'semantic silos' of ontologies" (Levy, 2011, pp. 108, 115, 120, 127).

Moreover, digital knowledge repositories are still populated by 'paper-like' document files, resembling linear content in accordance with outdated formatting and storing traditions, while needlessly adding fragmented and redundant copies to the mounting information load, further defeating the very attention human cognitive capabilities are able to master (Simon, 1971).

\section{Ideosphere's Intelligence and Extelligence Perspective}

Stewart and Cohen (1999) introduced the term 'Extelligence' for externally stored information; it forms the external counterpart to the intelligence of the human brain/mind and deals in information whereas intelligence deals in understanding; together they are driving each other in a complicit process of accelerating interactive co-evolution. Hughes (2011) reasons that human evolution and memes' endurances have not only thrived on big brain memory and communication technology with a high degree of accuracy but also on peoples' insatiable urge to use these technologies for the purposes intended, resulting in turning the familiar problem of information scarcity into a never before experienced ever-increasing attention-consuming information abundance (Schmitt, 2014b). As Simon (1971, p. 46) already noted over forty years ago, "in a knowledgerich world, progress does not lie in the direction of reading information faster, writing it faster, and storing more of it. Progress lies in the direction of extracting and exploiting the patterns of the world - its redundancy - so that far less information needs to be read, written, or stored."

Also, Extelligence as the representation of the expanding cumulative archive of human cultural experience and know-how is accessible and augmentable only by individuals who know how (Stewart \& Cohen, 1999). Accordingly, Levy (2011, p. 116) calls for the encouragement of autonomous personal knowledge management capacities in students as "one of the most important functions of teaching, from elementary school to the different levels of university" and Bedford (2013, p. 1) affirms, "Just as business, engineering and science education were key contributors to the development of advanced industrial economies in the $20^{\text {th }}$ century, KM education will provide key opportunities for growing a $21^{\text {st }}$ century knowledge economy." The current reality, however, has been perceived quite differently: "About 100 years ago, higher education restructured to meet the needs of the industrial age. It has changed little since, even as the internet has transformed life. Another revolution is needed to modernize universities and prepare graduates for a $21^{\text {st }}$ century working environment. We continue to prepare students as if their career path were linear, definite, specialized and predictable. We are making them experts in obsolescence. We are doing a good job of training them for the $20^{\text {th }}$ century" (Davidson, 2011). The consequences for a knowledge society are considerable (column I of Figure 2). 
At the organizational level, a major objective focusses on making the tacit knowledge (gained only experientially and difficult to articulate, explain, share - as opposed to formal or explicit knowledge) of knowledge workers explicit, so it can be measured, captured, stored, protected, shared, and further utilized, independent of its original individual source. In supporting firms in this endeavor, Nonaka's and Takeuchi's (1995) theory of organizational dynamic knowledge creation and its SECI Model (socialization, externalization, combination, and internalization) have become one of the most widely cited KM theories. The matter of the uncodified tacit knowledge (and its uncodifiable or explicable, intuitive or emotional subsets) remains one of the still most controversially discussed topics among academics. A further discord arises from the commercial interests to legally protect intellectual capital or knowledge assets via licensing, copyrighting, or patenting. Hence, 'Open Science' has come under threat "due to changes in intellectual property regimes, an increasing emphasis on data as scientific capital, and new models of electronic publishing. Emerging models of scholarship such as open access publishing and knowledge commons reflect efforts to reinstate the fundamental principles of 'Open Science'" (Borgman, 2003, p. 36).

Personal productivity is also compromised since digital libraries, e-learning platforms, or other eservices require separate individual or collaborative work spaces resulting in disconnected storage, repeated and redundant work with often severely limited sharing, import, and export opportunities. Unfortunately, the main stream educational and learning management systems are still focusing on centralized costly developments. With competing organizations determined to build their own and exclusive portals or social web platforms in order to capture their audience and users - with questionable utility for the individual - the wasteful treatment of clients' attention and efforts is likely to continue. Several more barriers holding back user-friendly personal KM solutions have been detected and have led to a plea for six Vital Provisions (Schmitt, 2014f, 2015c):

- Digital personal and personalized knowledge is always in the possession and at the personal disposal of its owner or eligible co-worker, residing in personal hardware and/or personalized cloud-databases.

- Contents are kept in a standardized, consistent, transparent, flexible, and secure format for easy retrieval, expansion, sharing, pooling, re-use and authoring, or migration.

- Information and functionalities can continually be used without disruption independent of changing one's social, educational, professional, or technological environment.

- Collaboration capabilities have to be mutually beneficial to facilitate consolidated team and enterprise actions that convert individual into organizational performances.

- The PKM system designs and complex operations are based on a concept, functionalities, and interventions which are clearly understood and are painlessly applied in practice.

- Accessibility to Shared Repositories is secured via a World Heritage Site of Memes maintained and curated by a Charitable Non-Profit Organization.

\section{The Alternative De-centralized Autonomous PKM Solution}

The PKM-related points in the bottom row (Figure 2) are to be elaborated on in the context of the IS-framework. What matters at this stage - in terms of Leavitt's Diamond Model - is that the proposed new concept prompts profound changes in each and every one of the four clusters/perspctives/components. This comprehensive shift made one anonymous peer reviewer of a prior paper wonder how the novel concept might "relate to Kuhn's ideas about science and paradigms and scientific revolutions", a valid point which will be taken up in the conclusions. 


\section{Cohen's IS-Framework for Abstract PKMS Mapping}

The upper half of Figure 3 shows one IS Framework in the informer-transformation-client sequence of the original (from left to right as exemplified in Figure 1) with another IS framework positioned at the lower half following the opposite direction. The combined chart can be interpreted as a matrix as well as a cycle. As a matrix, the upper half represents the real world's 'Intelligence and Extelligence' with the lower half corresponding to the novel 'PKMS System'; the left-hand side stands for the Information Space and its virtual and technological conceptualization while the right-hand side embodies the individual user, with the middle sector symbolizing the transformation channels.

In the instance of this paper, Cohen's two opposing IS-Frameworks (Figure 3) offer a generic meta-system at a high level of abstraction. A more specific representation of the PKM system proposed is provided by a set of additional models and methodologies represented symbolically by the square in the center of Figure 3 as well as by Table 1. In accordance with the 'MetaApproach' of Informing Science to Modelling, the IS-Frameworks portray the environment promoting informing, whereas the related subordinate models and methodologies portrayed embody central design elements of the blueprints on which the PKM concept and system are based. Accordingly, an initial overview is provided with the ensuing abstract segments of the Dual ISFramework as determined by their position (following a clockwise cycle from top left), before the associated subordinate models and methodologies are further detailed in the next section.

The real world's explicit and tacit knowledge exists in vectors and hosts and can be interpreted as memes and meme pools in an Ideosphere (I) which - in their role as informers (Ia) interact (I:P) with individual human clients or knowledge workers $(\mathrm{Pa})$. These individuals $(\mathrm{Pa})$ are simultaneously represented as PKMS clients by their personally hosted meme pool (Ib).

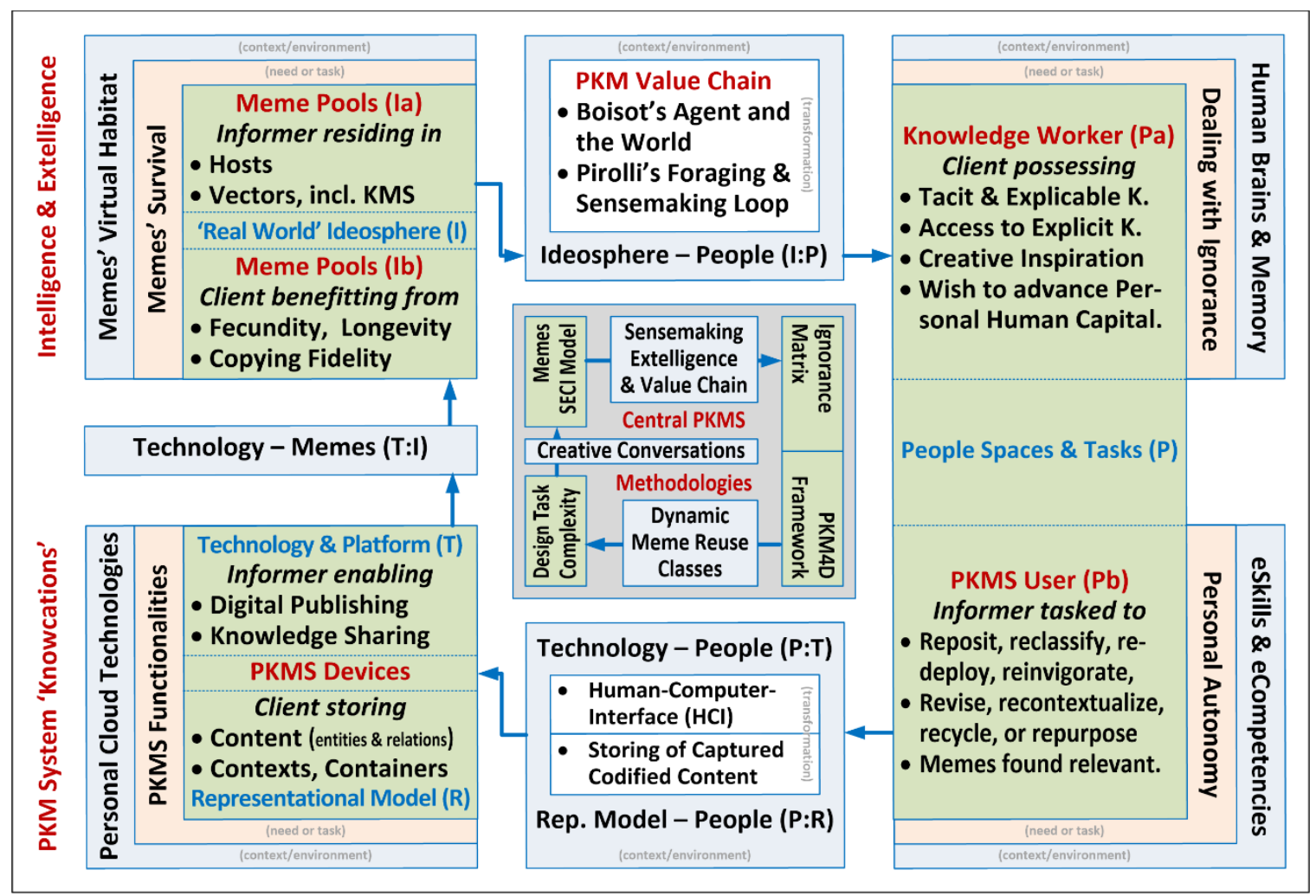

Figure 3: PKMS Concept as Two Opposing IS-Frameworks with related KM Methodologies 
As PKMS users/informers $(\mathrm{Pb})$, the knowledge workers communicate via the human-computerinterface (P:R) with the PKMS system/client to store/represent captured memes as information and knowledge in the PKMS repositories (R). In following user interventions, the PKMS-asinformer (T) utilizes its repositories (R) by either giving feedback (T:I) to its own user, publishing to vectors, or by sharing with or giving access to other hosts. This process serves the diverse meme pools/clients in the ideosphere by promoting or further spreading existing memes and/or by introducing new memes (Ib). The developing of vectors by means other than the PKMS is not relevant in our context and does not feature in the figure and its discussions.

\section{IS-Meta-Approach to PKMS Modelling and Blueprint}

Table 1 matches the central models and methodologies of the PKMS blueprint to the segments of the more generic IS-Framework depicted in Figure 3. Where Schmitt is cited, the models or methodologies have been substantially extended in comparison with the original work(s) of the prior author(s) whose work is duly referenced in square brackets and in discussions to follow. The term 'based on' in the text or in charts indicates that such amendments have been made by the author.

\begin{tabular}{|l|l|l|}
\hline \multicolumn{3}{|l|}{ Table 1: Generic IS-Framework Segments and their Specific PKMS Representations } \\
\hline Fig. 3 & IS-Framework Segments & PKMS Blueprint - Central Models/Methodologies \\
\hline I & Ideosphere: & 4.1 Memes (Dawkins, 1976; Schmitt, 20141) \\
& Memeplexes and Meme & 4.1 SECI Model (Nonaka \& Takeuchi, 1995) \\
& Pools & 4.7 Peoples' Personal Meme Pools and PKMS \\
\hline I:P & Transformation between & 4.2 Information-Space (Boisot, 2004) \\
& Ideosphere and People & 4.2 Sensemaking Loop (Pirolli \& Card, 2005) \\
& & 4.2 In-/Extelligence (Stewart \& Cohen 1999) \\
& & 4.2 PKM Value Chain (Schmitt, this paper \\
& & [Boisot, 2004; Porter, 1985] \\
\hline P & People Spaces \& Tasks: & [Armour, 2000; Kerwin, 1993; Schamanek, \\
& Knowledge Worker & 2012; UAHSC, 2012] \\
& & 4.3.2 PKM4D Framework (Schmitt, 2014k, 2015c) \\
& & [Johri \& Pal, 2012; Koltko-Rivera, 2006] \\
\hline P:R & Transformation between & Dynamic Meme Reuse Classes (Schmitt, 2015a-e) \\
& People and Representation & [Mitchell \& Mitchell, 2012] \\
\hline R & Representational Model & 4.5.1 Design Task Complexity (Gill \& Murphy, \\
T & Technology \& Platform & 2011) \\
& & 4.5.2 PKMS Design Task Complexity Cube \\
& & 4.5.3 Reducing Complexity and Entropy via PKMS \\
\hline R/T:I & Transformation between & 4.6 Creative Conversations (Levy, 2011) \\
& Representation and & 4.6 World Heritage Site of Memes (Schmitt, 2015c) \\
\hline & Ideosphere & \\
\hline
\end{tabular}

\section{Real World Mirroring the Virtual World of the Ideosphere}

A recent paper concentrates on the significance of the meme for the successful formation of autonomous PKM systems (Schmitt, 20141). The argument made follows up on Dawkins' (1976) concept of a meme as a unit of cultural transmission which evolves over time through a Darwinian process of variation, selection, and transmission. Able to self-replicate by utilizing mental storage in human hosts, memes influence their hosts' behavior to promote their further replication 
(Bjarneskans, Grønnevik, \& Sandberg, 1999). From the meme's-eye view, every human is a machine for making more memes, a vehicle for propagation, an opportunity for replication, and a resource to compete for (Blackmore, 2000). But, memes exist only virtually and have no intentions of their own; they are merely information pieces in a feedback loop with their longevity, fecundity, and copying fidelity being determined by their environment (Collis, 2003).

To survive, memes have to be able to endure in the medium they occupy and the medium itself has to persevere. They can either be encoded in durable vectors (e.g., storage devices, books, great art, major myths, or artefacts) spreading almost unchanged for millennia (Bjarneskans et al., 1999), or they succeed in competing for a host's limited attention span to be memorized (internalization*) until they are forgotten, codified (externalization*) or spread by the spoken word to other hosts' brains (socialization*) with the potential to mutate into new variants or form symbiotic relationships (combination*) with other memes (memeplexes) (G. Grant, Sandberg \& McFadzean, 1999) to mutually support each other's fitness and to replicate together (*-markings refer to comparable SECI Model stages (Nonaka \& Takeuchi, 1995; Schmitt, 2014m)).

Representing information, knowledge, and ideas (memes) as 'living' organisms introduces a further metaphor to the many employed already in the KM context, e.g., resource, asset, capital, property, process, network, or emotions (Andriessen, 2006, 2011; Schmitt, 2015e). It allows for the conceptualization of an 'Ideosphere' (Sandberg, 2000) as an "invisible but intelligible, metaphysical sphere of ideas and ideation" where we engage in the creation of our world (Kimura, 2005). Such a perspective not only historically accounts for the development of the different types of knowledge, innovations, and technologies, but also helps in advancing the creation of new knowledge. "If memes and their inbuilt ideas are able to flourish in a virtual 'Ideosphere' as their habitat of operation, PKM Systems aiming at supporting individual capacity and repertoire for innovation, sharing and collaboration are well advised to utilize the very same space and resources and to form a digital counterpart of this 'Ideosphere'" (Schmitt, 20141, p. 342).

\section{Transmission from Information Space to Individual Clients}

The 'ideosphere' can suitably be visualized using the three-dimensional Information Space Model (I-Space) formed by its axes of codification, abstraction, and diffusion (Boisot, 2004). Several Ispace charts and posters have depicted the relevant entities, workflows, and learning cycles of the PKMS concept, either fitting the underlying KM methodologies adopted (Schmitt, 2013b, 2013d, 2013g, 2014m, 2015e) or demonstrating the resulting PKMS processes (Schmitt, 2014d, 2015d).

Figure 4 shows a version which focuses on the main processes by following the foraging (1-3) and sensemaking (4-8) loops (Pirolli \& Card, 2005; Schmitt, 2013c) complemented by further PKMS service flows (a-j). The resulting closed learning cycle will be briefly recapitulated, since a detailed description has been provided in an earlier paper which also adds the corresponding hands-on user perspective and reports how the concept is applied by utilizing the PKMS prototype for the paper's creation (Schmitt, 2014d).

The two lower sections in Figure 4 (Hosts \& Vectors) visualize the memes' 'virtual' real world where individual human agents try to gain insights by gathering (foraging loop) data and information (memes) either from $(1 \mathrm{H}, 1 \mathrm{~V})$ and/or about sources $(\mathrm{jH}, \mathrm{jV})$ found to be relevant.

The two upper sections represent an agent's intelligence, working memory, and personal extelligence. Here, the memes gathered or thought up by an agent are constantly competing for his/her limited attention in order to be understood (internalized) and - for memes to survive - to be memorized or recorded in either pure, pre-edited, or already re-combined meme/memeplex versions. 


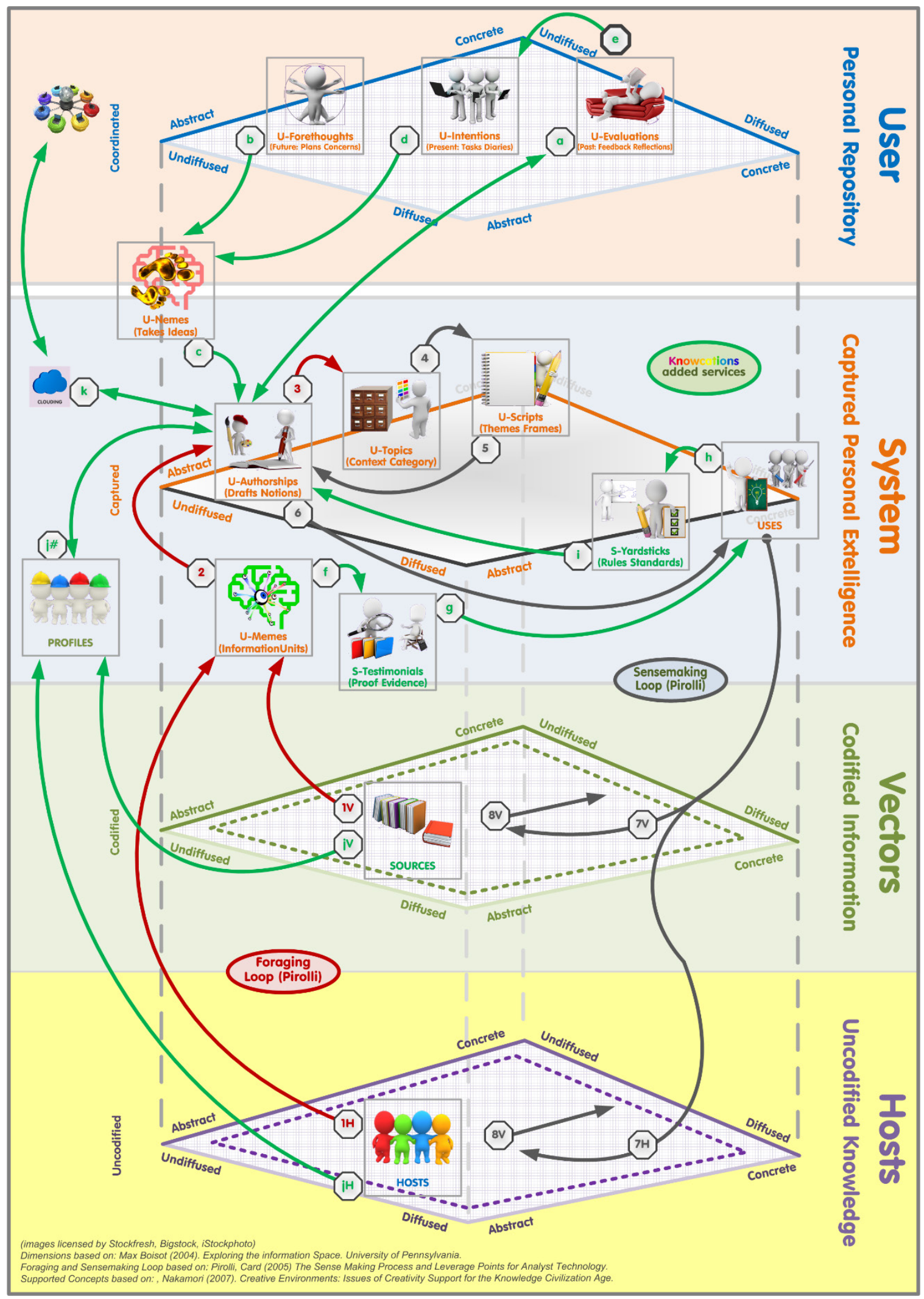

Figure 4: Ideosphere of the PKMS portrayed in Information Space (based on Boisot, 2004) 
In order to spread, memes and memeplexes have to be encoded by the agent in an informationcarrying medium (e.g., books, reports, papers, presentations, visuals, or spoken word) and disseminated to the two lower sections (externalized) where they might add to the world's extelligence $(7 \mathrm{~V})$ and/or are being passed between peers from brain to brain via learning and imitation $(7 \mathrm{H})$. Here, memes transmitted might be absorbed by other agents and converted into 'intangible', 'uncodified', or 'tacit' knowledge (socialized) as well as personal or organizational extelligence (combined). Eventually, the memes absorbed make an impact by becoming embedded in concrete practices, either in codified formats such as documents or products $(8 \mathrm{~V})$ or uncodified formats such as unwritten rules or patterns of behavior (8H) (Boisot, 2004; Pirolli \& Card, 2005; Nonaka, Toyama, \& Konno, 2000; Stewart \& Cohen 1999).

Figure 5 provides an alternative illustration (using Porter's (1985) shape and concept of a value chain) with emphasis placed on the transforming process and on added context relevant to upcoming discussions. It shows that - before memes are able to 'infect' an agent's brain - they have to successfully pass two filters (Boisot, 2004) which correspond to the agent's preferences, feelings, prior knowledge and experience, and actual states of ignorance, misconceptions, and erroneous beliefs. Any meme being able to make it through and being memorized, will, subsequently, not only influence the agent's action but also, potentially, impact the filters.

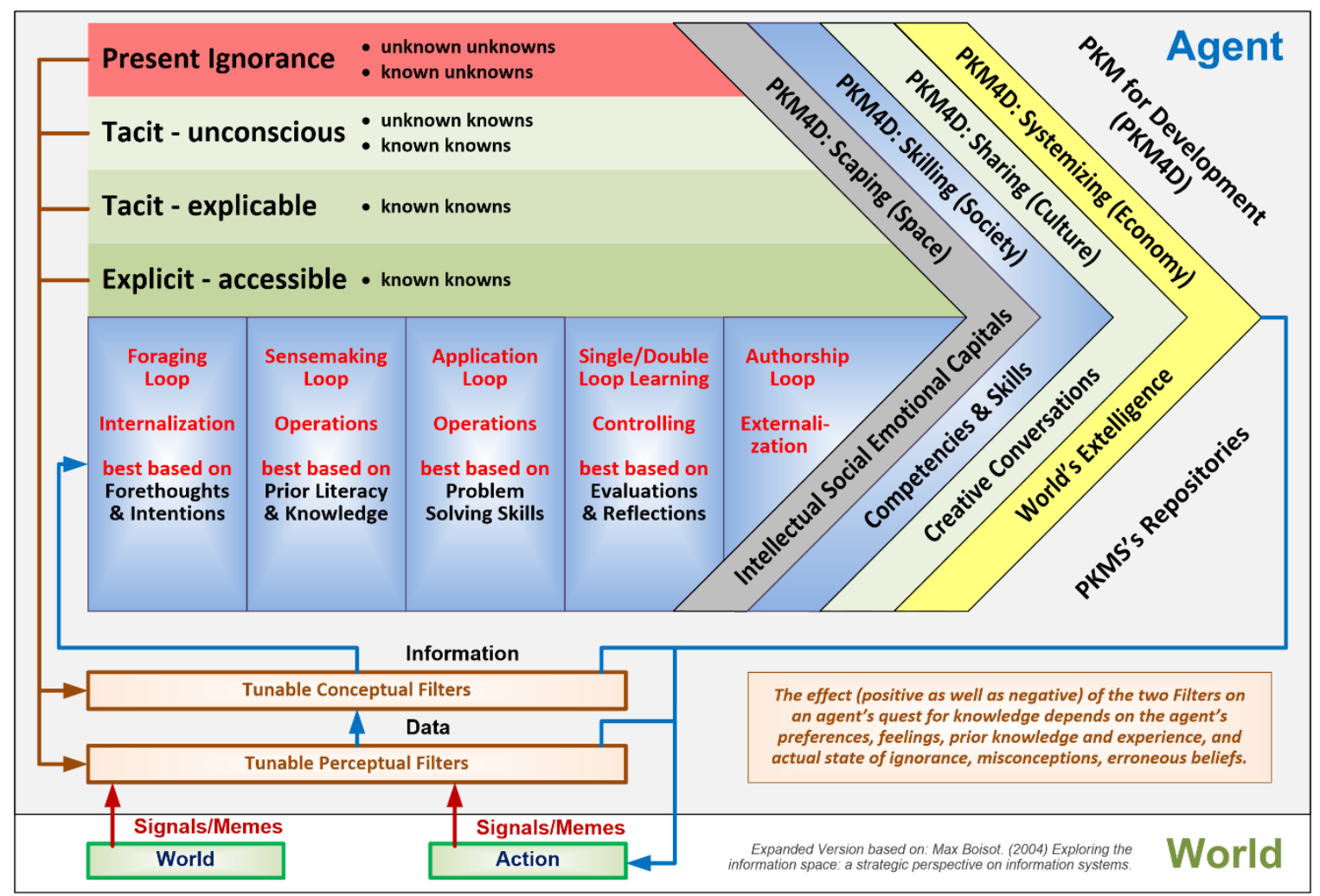

Figure 5: Value Chain of Personal Knowledge Development (based on Boisot, 2004) 


\section{Dual Role of Knowledge Workers as a Host and PKMS User}

\section{Knowledge workers role as a host of memes}

The last points made are of vital importance for personal KM, because, unfortunately, people who are unskilled in many social and intellectual domains "suffer a dual burden: Not only do these people reach erroneous conclusions and make unfortunate choices, but their incompetence robs them of the metacognitive ability to realize it" (Kruger \& Dunning, 2009, p. 30). The respective study results concur with the saying: "Not ignorance, but ignorance of ignorance, is the death of knowledge" (attributed to Alfred North Whitehead).

Fortunately, the 'Extended Ignorance Matrix' (further detailed in Schmitt, 2014k, 2013e; based on Armour, 2000; Kerwin, 1993; Schamanek, 2012; UAHSC, 2012) provides agents with a fitting classification system to address the concerns and with it some means to overcome them. Figure 6 depicts an updated version with related learning cycles (from $1 \mathrm{x}$ to $8 \mathrm{x}$ ) and associated wastes (from \#1 to \#8). The grey backgrounds depict an agent's active memepool, while the light red background depicts external memepools; the red boxes symbolizes an agent's ignorance including 'false' knowledge, denials, and taboos tainting the agent's own meme pool. Of particular relevance is a lack of process knowledge and suitably efficient means to become aware of relevant 'unknown unknowns' and how to tackle them (management of learning at the meta-level).

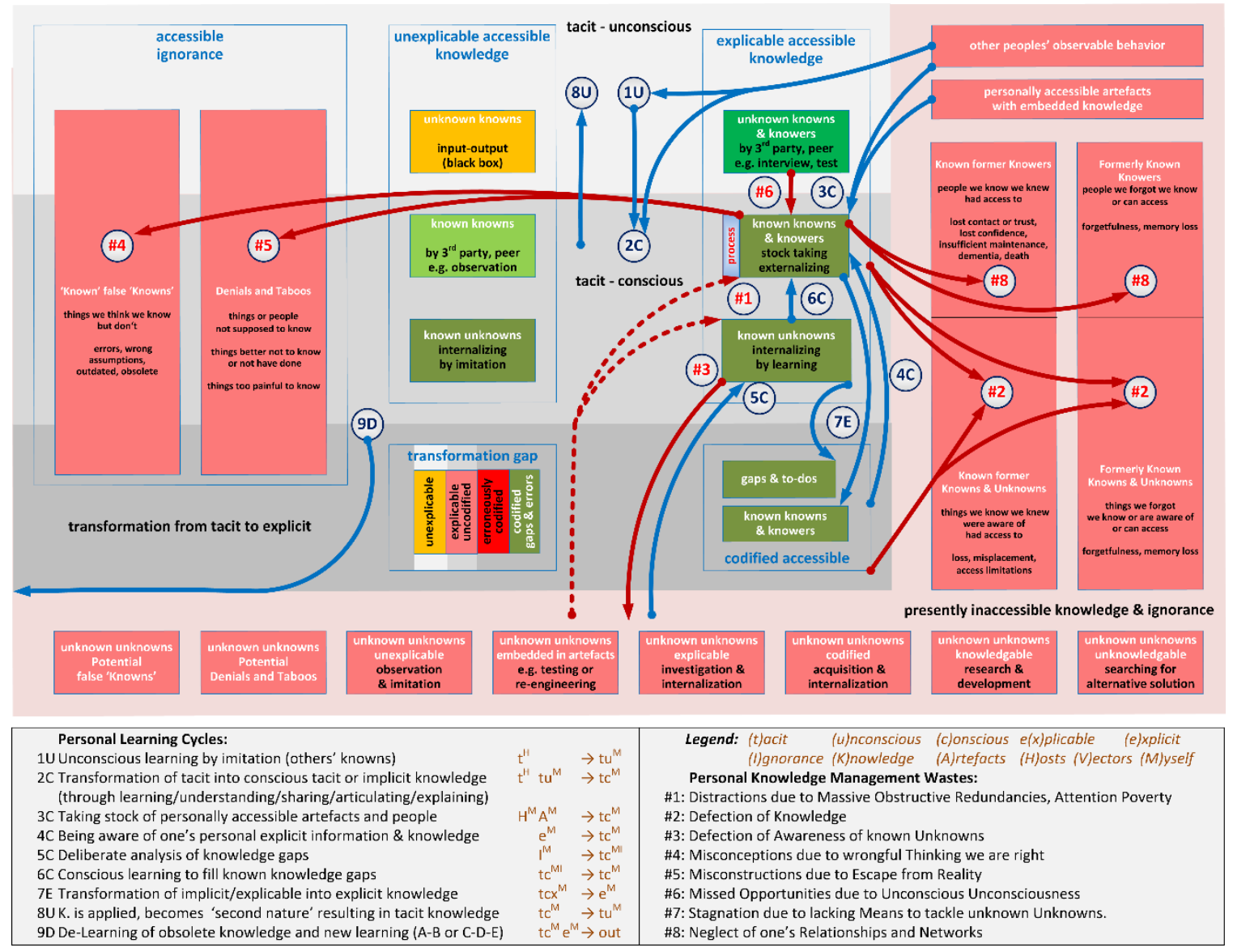

Figure 6: Extended Ignorance Matrix (based on Armour, 2000; Kerwin, 1993; Schamanek, 2012) 
It follows that developing our intellectual capital requires deliberate efforts and more advanced assistance and tools "for identifying and filling knowledge gaps, detecting and correcting flaws, and deciding on suitable means for evaluating and advancing our repositories including the recording of related to-dos, progress, processes, and feedback" (Schmitt, 2012, p. 1; 2014k).

To also occupy the adverse role of an informer informing others, the agent would be simultaneously positioned in the left upper section (Figure 2) and his/her clients in the right upper section. It means that for an agent without the prospective PKMS support, the lower half of Figure 3 would not be relevant, neither would be the 'PKM4D' labelled section in the upper right part of Figure 5.

While this section's discussion has, so far, concentrated on the more 'technical' needs concerned addressing the ignorance issues, the agenda of the PKM4D (PKM for Development) focusses on the outcomes hoped for benefitting an agent, his/her associates, and society.

\section{Role as a PKMS user influenced by the PKM4D framework}

The PKM4D framework (Figure 7) has been introduced in a prior paper (Schmitt, 2014k) and refers to twelve criteria which integrate Johri's and Pal's (2012) four ICT4D-criteria and are fully aligned to Maslow's Extended Hierarchy of Needs (Koltko-Rivera, 2006) (see Figure 7 left). The framework, as further portrayed in a presented paper (Schmitt, 2015a), allows for a differentiated breakdown of the PKMS's potential impact - as indicated by the matching colors - on one's personal productive space (scaping), on society's need for capacity development (skilling), on the means for collaborations across professional cultures (sharing), and on the innovative processes benefitting a knowledge economy (systemizing).

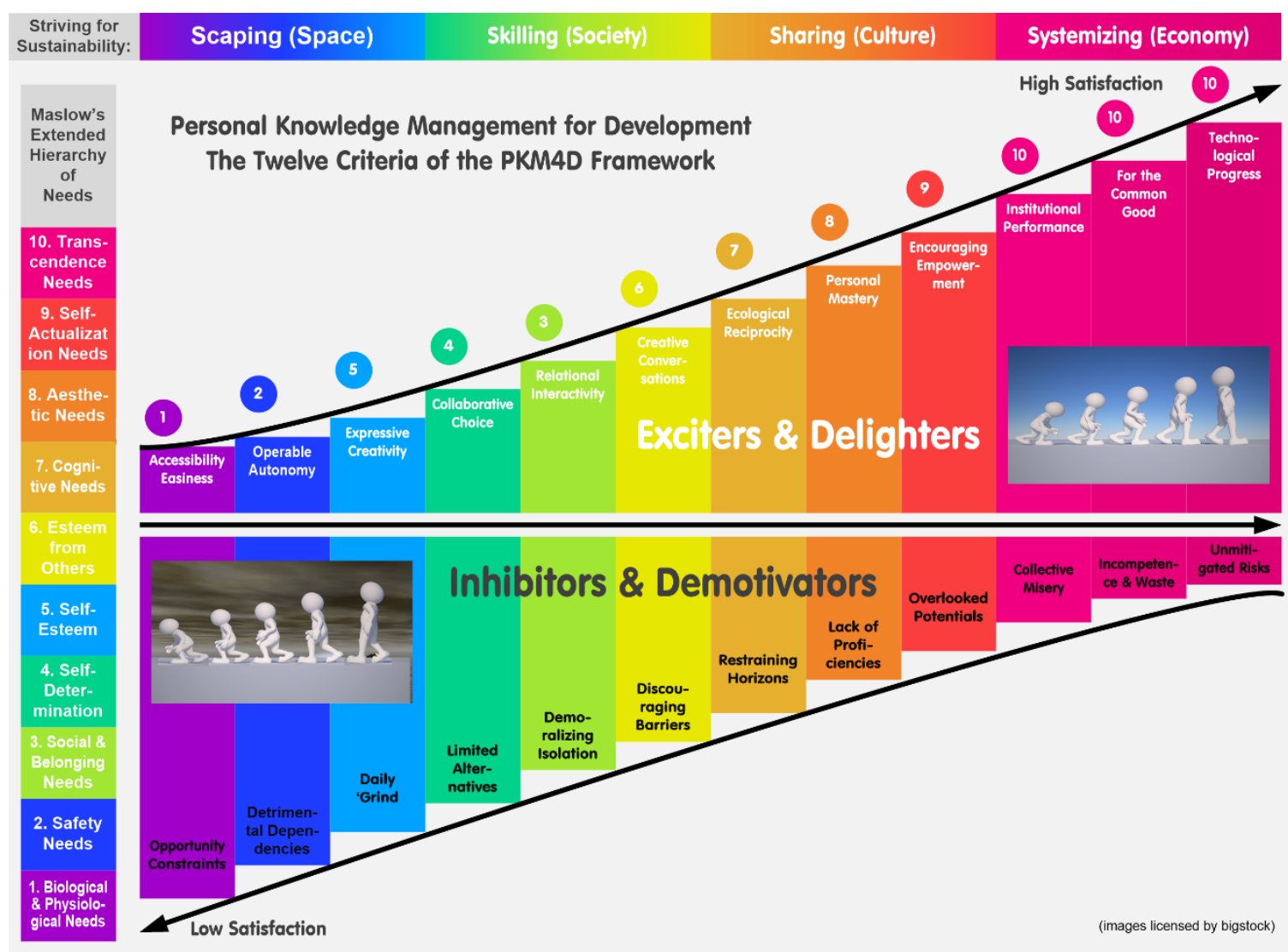

Figure 7: PKM4D Framework with Delighters-Exciters and Inhibitors-Demotivators 
The arguments made follow the principles of the Kano Model and Herzberg's Two Factor Theory (Herzberg, 1987: Kano, Seraku, Takahashi, \& Tsuji, 1984). While the support of the PKMS functionalities (as detailed in Schmitt, 2014k) will positively impact the individual at the different stages portrayed, its absence and the lack of other potentially appropriate tools will yield detrimental effects on individuals; the same applies on the aggregate societal level of the various opportunity divides currently discussed (e.g., access, digital, learning, knowledge, innovation).

\section{Transmissions between PKMS User and PKMS Devices}

As pointed out, "If memes and their inbuilt ideas are able to flourish in a virtual 'Ideosphere' as their habitat of operation, PKM Systems [...] are well advised to utilize the very same space and resources and to form a digital counterpart of this 'Ideosphere"' (Schmitt, 2014l). In line with this recommendation, the virtual process flows of the foraging and sensemaking loops in the two upper sections (Figure 4) also correspond to the digital ones. Accordingly, the PKMS user interface and the structures of the PKMS repositories facilitate the addition and manipulation of memes selected by the user. To present the respective transformations and tasks, Figure 8 makes use of a recently suggested 'Organizing Typology for Digital Content Users' (Mitchell \& Mitchell, 2012), although the arrangements and terms have been amended to better fit the meme context.

Any physical content and meta-data of a meme can be simply reposited from its original source as-is or changed by modifying its attributes (codification, context, container or asset). However, the clockwise process flow in Figures 4 and 5 depicts a theoretical idealistic chain of events. The reality is characterized by repeatedly moving back and forth, a heuristic iterative practice of continuous improvement until a satisfactory draft of the intended output has been accomplished.
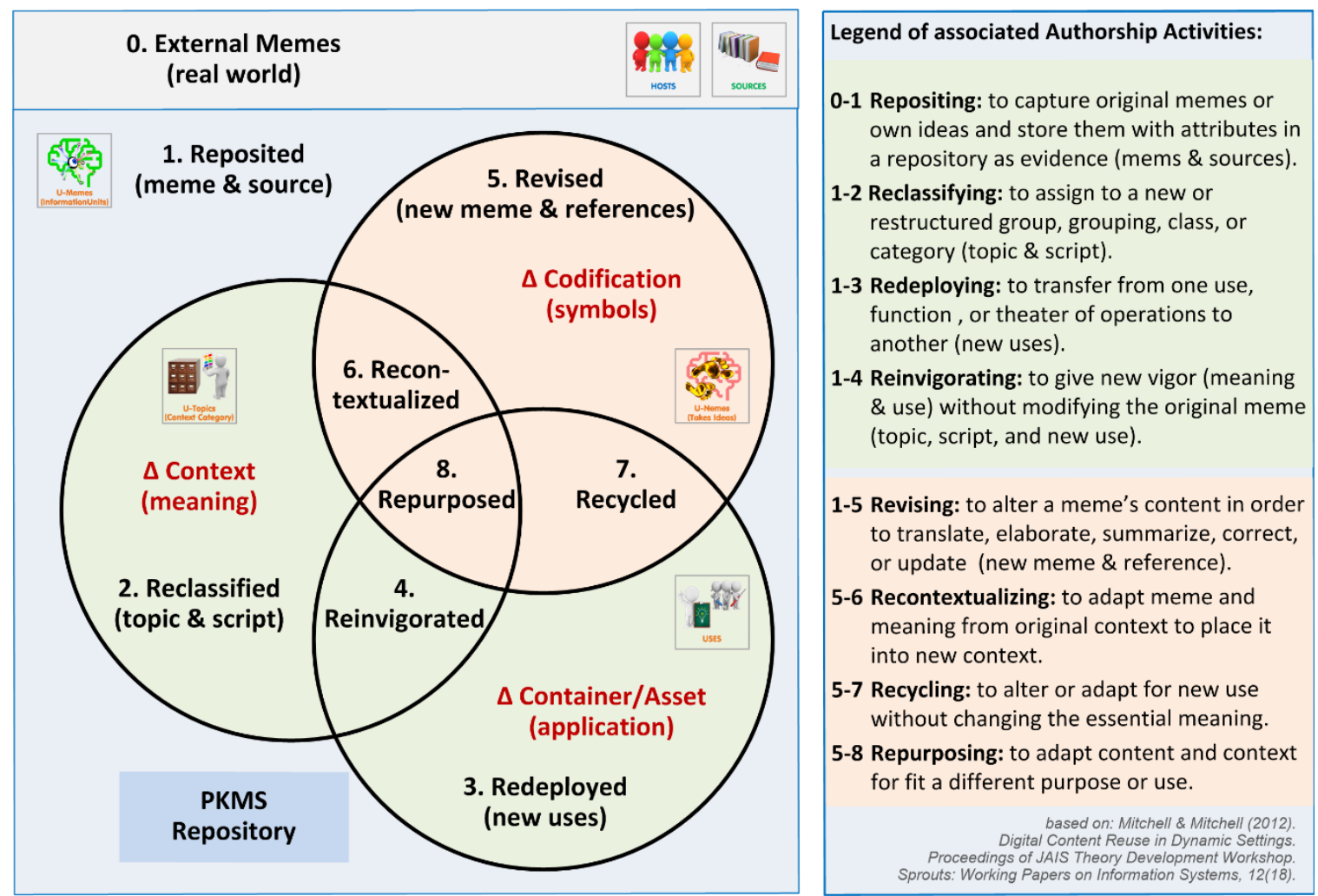

Figure 8: Dynamic Meme Reuse Classes and Attribute Modifications (based on Mitchell \& Mitchell, 2012) 
“Thus, by digitally capturing, referencing, classifying, and reusing memes (representing basic information units), the system allows us to recall, sequence and combine stored units with our own newly inspired meme creations ('nemes') for integration in any type of [ignorance diminishing undertaking or] authoring and sharing activity one would like to pursue. As a result, a user obtains the means to retain and build upon knowledge acquired in order to sustain personal growth and facilitate productive contributions and collaborations between fellow learners and/or professional acquaintances" (Schmitt, 2013b, p. 4).

\section{Multiple PKMS Roles from Representation to Publishing}

With the issues raised, one wonders how a system based on the personal knowledge management concept would be able to better serve the growing creative class of knowledge workers and the innovation agenda of knowledge economies compared to current solutions? How can personal devices help in mastering the ever-increasing information abundance, the changing spheres of work, the widening digital and innovation divides, and the needs for self-development and ecollaboration? Given Davenport's (1994) widely quoted early definition of KM as the process of capturing, distributing, and effectively using knowledge, how can such basic activities be redesigned to make a difference? In order to frame an answer one has to establish first where the growing complexities of the past decades affecting KM have led us.

\section{The significance of design task complexity}

Gill and Murphy (2011) have proposed a conceptual scheme to map design task complexity corresponding to three dimensions (and measures): Objective Complexity (ruggedness [R]), Problem Space Complexity (path entropy [E]), and Unfamiliarity (perceived difficulty [D]).

Objective Complexity rests on three primary sources (Wood, 1989):

- Component Complexity refers to the number of different elements and components or, in the PKM context, the relevant 'Entities' and their associated 'Content' to be stored, for example, persons, teams, communities, organizations, domains, sectors, regions, articles, books, chapters, websites, events, systems, evidence, or ideas.

- Coordinative Complexity refers to the level of interaction between these components, respectively the 'Relationships' between the PKM 'Entities' captured, for example, professional experience, research activity, education, outcomes, achievements, formal or informal relations, roles, references, or ideas and people contributing to a paper or book.

- Dynamic Complexity refers to the degree to which inputs, relationships, and outputs change over time, respectively to the durations of 'Entities' and 'Relationships' which determine their legality, authority, validity, actuality or state-of-the-art, for example, office holders, occupancies, contractual responsibilities, expiration dates, expertise attributed to or powers vested in someone.

Rising populations and higher innovation rates mean that not only the number of entities to deal with grows, but that the potential relationships are subjected to a combinatorial explosion. Accelerating change also renders the acquired know-who/how/why/where/when/with/abouts more rapidly obsolete than ever before. Often, simple overrides of records do not suffice, since the dynamics have to be logged to cater for version management or forensic needs.

The term ruggedness applied refers to the design fitness landscape where many distributed local maxima exist for different values of the multiple design attributes available for selection. Unfortunately, for knowledge items in the KM context these attributes increasingly comprise outdated information often only partially copied with vital links and publishing dates missing, resulting in introducing more and more local minima in expanding territories of unfitness. 
"The problem space describes the internal representation within the mind of a designer" (Gill \& Murphy, 2011, p. 2). Hence, complexity increases with the size of the problem space, the extent of constraints, and the number of paths leading to a positive or negative outcome; it decreases with growing expertise of the designer or the reversibility of steps taken, if backtracking is possible. Regrettably, the changing spheres of work are not very accommodating. With specializations and domain-specific knowledge on the rise, work has suffered from a process of fragmentation which will continue to accelerate. Implications for professionals include slipping control over constant interruptions, the loss of time for real concentration, less learning by observation and reflection, and the advice to become knowledgeable in more than one single area although the time for personal mastery (said to require 10,000 hours) is already in short supply (Gratton, 2011).

Unfamiliarity "represents the absence of task-specific knowledge". The difficulty perceived is high when there is little guidance and one is "forced to rely on general knowledge and unreliable techniques" and to a large degree on one's working memory (Gill \& Murphy, 2011, p. 2). Disappointingly, there are no adequate tools available to ease the handling of these ill-structured tasks. "While today we have many powerful applications for locating vast amounts of digital information, we lack effective tools for selecting, structuring, personalizing, and making sense of the digital resources available to us" (Kahle, 2009, p. 32).

\section{PKMS Design Task Complexity Cube}

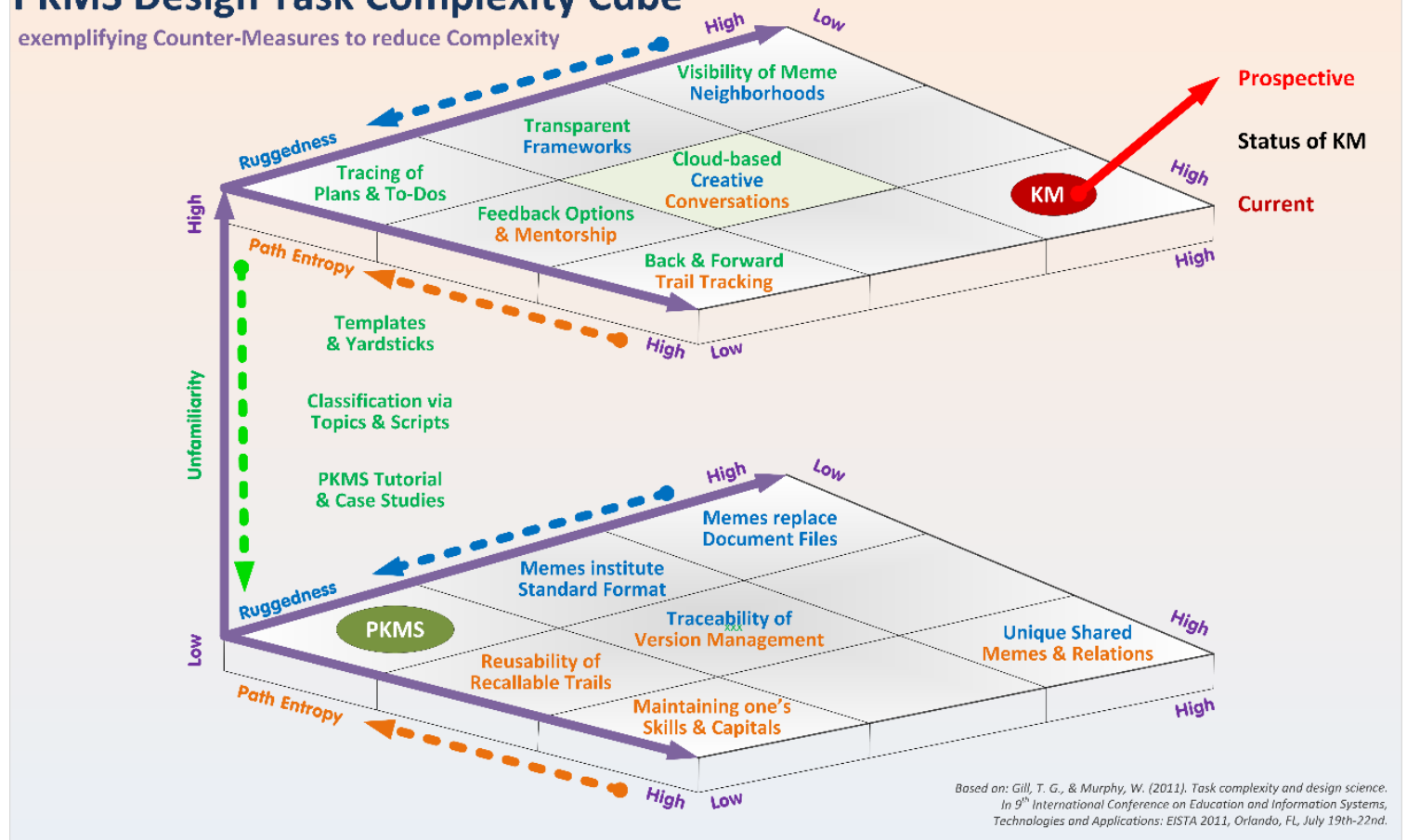

Figure 9: PKMS Design Task Complexity Cube (based on Gill \& Murphy, 2011)

\section{Anticipating a likely scenario of KM design complexity}

A brief assessment of the three criteria places the current complexity status of KM design activities at the highpoint of the PKMS Design Task Complexity Cube (Figure 9). What might lie ahead has been explored in a prior paper (Schmitt, 2014b). The development already under way, exploiting the opportunities of cloud-based platforms and applications, is said to become the fourth industrial revolution and is called the 'Industrial Internet' (Evans \& Annunziata, 2012). It 
will facilitate machine learning, machine-to-machine communication, big data analytics, and the Internet of Things by incorporating networked sensors and software into goods and machines resulting in the self-organizational capability of complex value chains. As a consequence, even more information will be generated, copied, varied, and selected to be interpreted by 'Big Data' applications and distributed for human attention. The chart represents this scenario with the rising red arrow.

It follows that a prospective PKMS solution ought to first find ways to scale down each one of the complexities discussed in order to subsequently create 'productive' spaces for efficient storage, improved learning, assisted authorship, and innovative knowledge utilization which are able to better absorb and share prospective knowledge advances. The green, blue, and orange colors exemplify the respective directions and related counter-measures (Figure 9) to be further discussed.

\section{Identifying counter-measures to reduce KM design complexity}

"The distinction of a Personal KM System, in contrast to its organizational counterparts, is to enable self-reflecting monologues of its user over life-long-learning periods of educational, professional, social and private activity and experience. In these conversations with self, the knowledge under review is biographically self-determined and presents itself as a former state of personal extelligence captured in external extensions of the individual knower's mental storage capacity" (Schmitt, 2014f, p. 17). Accordingly, the scope of the problem space is not just limited to a designer's mind, but also includes the 'ideosphere' as represented in his/her personal KM repository. To reduce the path entropy alluded to, both parts of the term have to be addressed.

Entropy, defined in terms of information theory as the opposite of information, organization, order, or improbability (De Rosnay, 1979, p. 146), has to be addressed by supporting the personal learning cycles and by avoiding the personal $\mathrm{KM}$ wastes as indicated in the Extended Ignorance Matrix (Figure 6). It means cutting down on current 'PKM' practices as portrayed in the very first paper of the series, "At the preservation level, we still take copies and store them in diverse arrays of devices or make mental notes only. Over time, copies deteriorate, memories fade and with it the ability to recall the locations and contents of our fragmented personal knowledge inventories and archives. Nevertheless, we are unable to part with our accumulated hard and soft copies which slowly but steadily lapse from potential value towards dead ballast" (Schmitt, 2012, p. 1). This sorry state of personal knowledge preservation has been confirmed by a brief PKM Needs Survey based on Flickr Images (Schmitt, 2014k, Figure 2).

Path, in our context, refers to a "series of transitions through the problem space" (Gill \& Murphy, 2011 , p. 2). In proposing the 'Memex', an imaginary PKMS ancestor celebrating its $70^{\text {th }}$ anniversary as an inspiring idea never been realized (Davies, 2011), Vannevar Bush (1945) reminds us that the human mind operates by association, not by indexing. One cannot hope that artificial means "equal the speed and flexibility with which the mind follows an associative trail [analogy of path], but it should be possible to beat the mind decisively in regard to the permanence and clarity of the items resurrected from storage." Thus, by preserving a person's non-fading trails "of his interest through the maze of materials available to him", "he can reacquire the privilege of forgetting the manifold things he does not need to have immediately at hand, with some assurance that he can find them again if they prove important." As a result, intellectual "excursions may become more enjoyable" and by sharing the trails acquired during excursions or for own publications, "the inheritance from the master becomes, not only his additions to the world's record, but for his disciples the entire scaffolding by which they were erected".

A recent paper has visualized and exemplified the potential of lowering path entropy by strengthening the capturing of trails (Schmitt, 20141), and further papers based on recent presentations and currently reviewed (Schmitt, 2014j; 2015b) as well as papers in progress provide further de- 
tail in respect to digital scholarship, individual curation, and the creation and traceability of knowledge assets.

Bush (1945) also noted (seventy years ago!) the "growing mountain of research" and the "increased evidence that we are being bogged down today" as "specialization becomes increasingly necessary for progress, and the effort to bridge between disciplines is correspondingly superficial." "Professionally, our methods of transmitting and reviewing the results of research are generations old and by now are totally inadequate for their purpose", while "truly significant attainments become lost in the mass of the inconsequential." "The difficulty seems to be [...] that publication has been extended far beyond our present ability to make real use of the record". Since then, information scarcity has turned into abundance with an emerging need for attention management (Simon, 1971), and Nielsen (2011) urges to take advantage of today's online realities in order to remove barriers that prevent potential contributors from engaging in a wider sharing and faster diffusion of their ideas, sources, data, work-in-progress, preprints, and/or code for the benefit of more rapid iterative improvement.

The initial paper (Schmitt, 2012, p. 2) summarizes these shortcomings in the personal context: "At the conceptual level, abstract models and improvised practices (mis-)guide the integration of newly gathered data, information, and experiences into existing fragile frames of personal knowledge. Information supply is ever expanding and so are cross-publicized fragments of media and research outputs. Instead of concentrating on the creative or innovative objectives set, time is lost in dealing with redundant findings and on mundane tasks of sorting, ordering, and referencing."

The traditional paper-based publication is "designed to contain all the information required to stop inquiries within the [publication's] topic." But now "our [digital] medium can handle far more ideas and information" and it also presents "a connective medium (ideas to ideas, people to ideas, people to people)." With its abundant capacity, the Internet "has removed the old artificial constraints on publishing - including getting our content checked and verified. The new strategy of publishing everything we find out, thus, results in an immense cloud of data, free of theory, published before verified, and available to anyone with an Internet connection." As the traditional physical filters and authorities lose their grip, "we can now see every idiotic idea put forward seriously and every serious idea treated idiotically". Moreover, "our information technologies are precisely the same as our communication technologies, so learning a fact can be precisely the same as publishing a fact to the world" (Weinberger, 2012, pp. 12, 21, 35).

So, the boundaries of Objective Complexity are constantly pushed, either by content (or fractions of it) replicating as redundant, fragmented, distorted, or incorrect copies (adding to the trivial chatter populating the search engine listings and consuming our attention) or by content mutating due to the modification of facts or ideas stated before (which the physics of paper prevented). When faced with a similar problem of compromised integrity and unmaintainable redundancy, earlier flat file databases were replaced with the normalized table structures of the relational database design approach. The meme-based PKMS concept not only supports preserving paths and trails between its basic information structures, but also strives to prevent the unnecessary replication of identical memes lumped together in redundant cluttered knowledge containers, cumbersome to trace but effective in bloating knowledge repositories. The benefits are described in the 'Transmission from the PKMS to the Ideosphere' section.

Unfamiliarity applies to the process of capturing, distributing, and effectively using knowledge as well as to the e-skills required to operate a PKM system device. The importance of education as one of the means to address unfamiliarity has been stressed by Levy (2011), Bedford (2013) and Davidson (2011), as cited before. In the PKMS Meta-Concept (Schmitt, 2014m), this educational dimension plays an important role. It is supported by using the memes of the papers published 
and referenced as one of the test data sets of the prototype, ready to subsequently be transformed into the system's tutorial as well as one of its case studies. Furthermore, the content provided will be further utilized in a book, as the basis for two face-to-face course designs as well as for an elearning version.

Supporting tool, process, and content familiarity is also strengthened by providing further memebased examples (e.g., cocktail database, a family tree, personal biography, personal library, graduate program accreditation example), flexible options to view associated memes, to track trails, and to engage in authorship (user interface), extendable classification frameworks (called topics and scripts), templates (e.g., for a business plan), yardsticks (e.g., accreditation criteria) as well as the means to plan, trace, and control one's and others' actions and to dos (contributing to one's social and emotional capital).

Moreover, the PKMS supports the notion that knowledge and skills of a knowledge worker are portable and mobile. As professionals move from one project or responsibility to another, they will want to take their version of a knowledge management system with them. "In this context, an à-jour, well-maintained PKM System takes on the role of the [digital] quartermaster for sizeable portions of one's Intellectual, Social, and Emotional Capital" (Schmitt, 2012, p. 5).

\section{Transmission from the PKMS to the Ideosphere}

A recent paper has exemplified the benefits of the transmission by being the output of the very Personal Knowledge Management Technology it describes (Schmitt, 2014d). However, the paper produced by the system resembles a one-dimensional and finalized printed or electronic copy (just like this paper), which is quite different compared to the virtual version still present in the author's 'Knowcations' knowledge repository.

In the latter, any individual meme consists of its content, its associated meta-description, its multiple relationships with other memes, and, in a more comprehensive sense, of all its close and wider meme relationships (including content, meta-data and relations). Publishing a paper or pdfcopy is just a dissemination of a static snapshot taken from an immediate virtual subset in the PKMS repository, which includes a first level of ordered memes together with its first-level relationships displayed as list in the reference section.

The virtual version, by comparison, is information-rich, multi-dimensional, and comprises many more causative references which might still grow further in number and quality by being cited, amended, or added to. Firstly, any reference to hosts and their role (e.g., authors, editors, information suppliers, organization) opens up access to their background links as assembled by own or shared data in the Profiles base. Secondly, any meta-data generated during the paper authoring project has been kept and can be accessed and any links with other external entities can be followed, if access and copyrights permit. Thirdly, any meme not newly created points to its original version, so that its neighboring memes or sections in its original source (if included) can be accessed, either digitally or as hardcopy. Any of these original memes might have been used and/or might be used further in the future in the same or different contexts, as an original, paraphrased, or re-purposed version which again can be visited, if access and copyrights permit.

Thus, circulating the entirety of the information-richer virtual version of a particular paper digitally among a community via creative conversations and shared repositories results in significantly added value (see example visualized in Figure 10), but is also far more complex.

Firstly, it requires that receiving systems share compatible structures and formats. Secondly, the inclusion of memes linked by uninterrupted levels of relationships can end up in extensive data quantities; user interventions might be required for where to draw the line, and system rules also have to cater for confidential or copyrighted memes, ensuring the overall consistency and integri- 
ty of the record set finally to be transferred. Thirdly, rules have to be in place to determine which attribute modifications (Figure 8) are still permissible by the initial author and sharing community members without reverting to an entirely new meme version automatically linked to its original parent meme.

The shared aggregated trajectories of the distinctive memes across multiple PKMS users provide a multitude of enhanced options to engage in one's topics of interest (and also require further means to manage this choice). Thus, collaboratively interlinking knowledge bases to collectively trace, harvest and utilize accumulated knowledge subsets based on shared records will overall reduce redundant content and improve the productivity of information seekers and suppliers alike (Schmitt, 2014c).

A paper presented (Schmitt, 2015a) has looked at the PKMS's sustainable impact on society will propose to host the aggregated extelligence shared by PKMS users in a centralized cloud-based knowledge repository (with references duly made to original authors) safeguarding public access secured by the set-up of a non-profit repository, named 'World Heritage Site of Memes'.

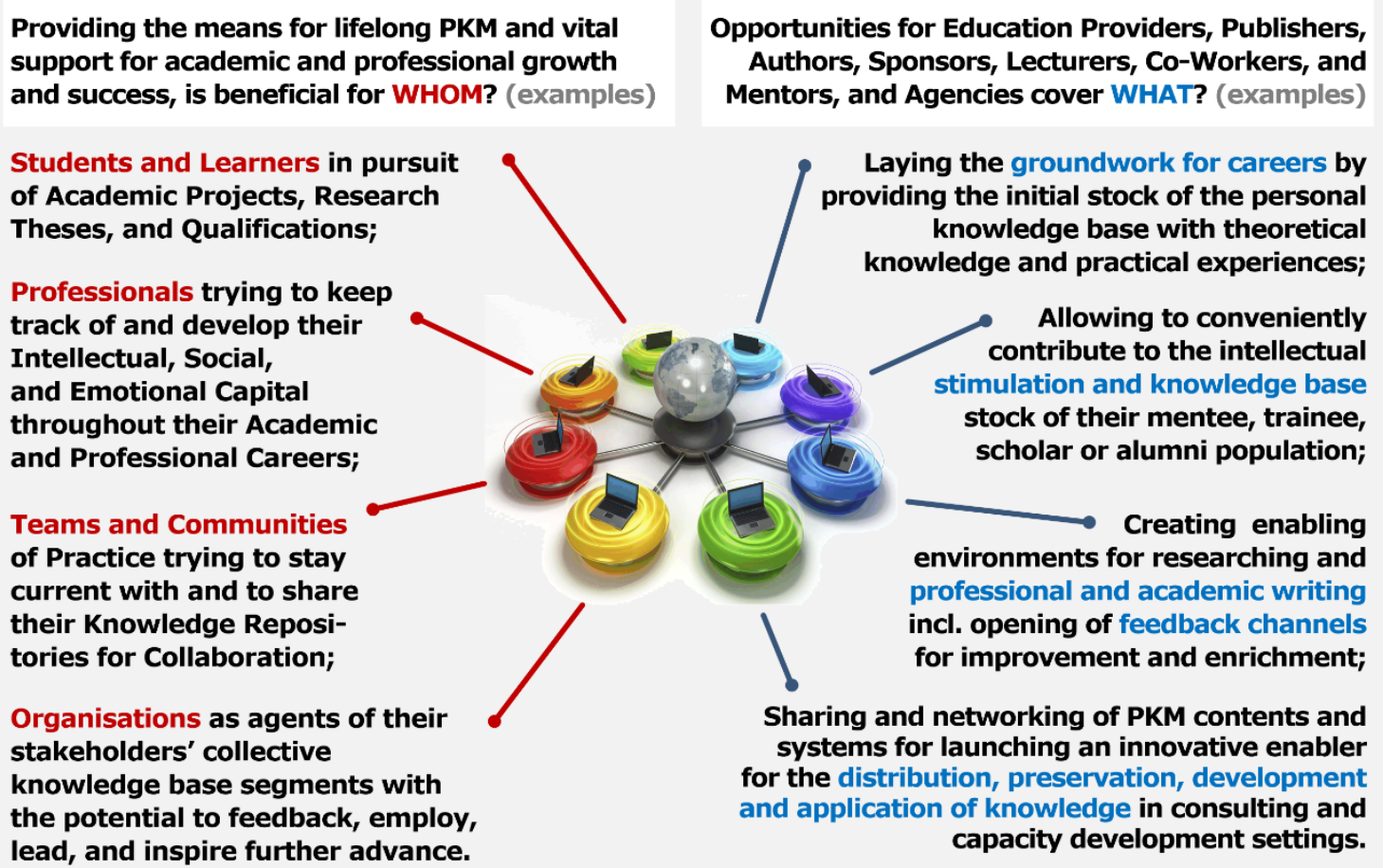

(images licensed by istockphoto)

Figure 10: Creative Conversation Clusters of Individual PKMS Devices (Schmitt, 2013f)

\section{Peoples' Meme Pools as Beneficiary of PKMS Devices}

People conserve and manage personal information for future consumption and exploitation. It's not just that people passively keep this information, they also make strenuous attempts to organize it in ways that will promote future retrieval by persistently engaging in active and extensive preservation and curation behaviors in their information environments (Whittaker, 2011). With the support functionalities presented, a meme-based PKM System is able to provide continuous life-cycle support from trainee, student, novice, or mentee to professional, expert, coach or leader. 
Yet, an even larger potential exists, when the users of these distributed autonomous PKMS capacities engage in knowledge sharing and 'Creative Conversations', so that their personal devices facilitate the emergence of the distributed processes of collective extelligence and intelligence, which in turn feed them (Levy, 2011, p. 116). Levy's term 'Creative Conversations' motivated the sketching of a respective 'Exemplary Scope' of PKMS devices (Figure 10; Schmitt, 2013f).

Establishing cloud-based PKMS repositories and devices would enable such a setting ensuing the six vital provisions alluded to. It would initiate the departure from the current heavyweight, prohibitive, centralized, top-down, institutional developments with preference given to grass roots, bottom-up, lightweight, affordable, and personal applications across a multitude of platforms as described in Figure 2. However, the strengthening of individual sovereignty and personal applications is not meant to be at the expense of Organizational KM Systems, but rather as the means to foster a fruitful co-evolution. For this, a common denominator of shared KM theories and practices has been established; a recent paper (Schmitt, 2015e) identifies forty-eight renowned KM constructs and methodologies which have been integrated into the meme-based PKMS concept.

Accordingly, the aims of the PKM System can be widened to aid life-long-learning, resourcefulness, creativity, and teamwork of individuals throughout their academic and professional life and as contributors and beneficiaries of organizational and societal performance. Such a scope offers appealing and viable opportunities for stakeholders in the educational (Schmitt \& Butchart, 2014), professional (Schmitt, 2013f), and developmental (Schmitt, 2014a) context.

It might also well qualify as one of the 'new media', Nielsen referred to when he suggested the wider sharing and faster diffusion of knowledge "to carry the same kind of cachet that papers do today" (Nielsen, 2011, p. 197) and definitely corresponds to Wiig's (2011) notion of the importance of the individual: "The overall performance and viability of societies and enterprises result from innumerable small actions by individuals. Small personal 'nano actions' combine with larger departmental actions that combine to create consolidated enterprise actions that result in the performance of the whole organization." Accordingly, "the root objective of PKM is the desire to make citizens highly knowledgeable. They should function competently and effectively in their daily lives, as part of the workforce and as public citizens" (Wiig, 2011, pp. 230, 235).

\section{Conclusions, Revolutions, and Paradigms Shifts}

The objective of this paper has been to validate the proposed PKMS concept and prototype against the systems thinking approach of Informing Science. By applying Cohen's Framework, Leavitt's Diamond Model, the IS-Meta Approach, and Gill's and Murphy's Three Dimensions of Design Task Complexity, the more specific KM models and methodologies central to the PKMS concept have been aligned, introduced, and visualized. The extent of this introduction offers an essential overview which can be deepened and broadened by using the cited URL and DOI links pointing to the freely available resources of the author's prior publications. These papers also further detail the scope of benefits of the proposed concept and system for the individual, organizations, and society and introduce a range of further renowned KM methods and methodologies which have been integrated in the PKMS design.

As a further result, the paper has reinforced the value and wide-ranging applicability of the Informing Science Framework, in particular, in the context of knowledge management. In the conclusions of their paper, Gill and Murphy (2011) asked for the testing of their proposed conceptual scheme, an undertaking which this paper has successfully realized by mapping the particular design tasks' complexities to the PKMS reasoning approaches and types of artifacts and models.

The arguments put forward concur with the scenario presented by Levy (2011, p. 127), "Just as computer science underwent a revolution in the 1980s with the widespread use of personal computers, it is possible that Knowledge Management will in the twenty-first century experience a 
decentralizing revolution that gives more power and autonomy to individuals and self-organized groups."

So, how does the revolution implied by Levy compare to Kuhn's notion? Before taking a closer look, one has to take note of the discussion about KM respectively PKM. Is KM already a well established field of research or is it still in an evolving and developmental state in terms of its ideas, systematization, and application (McFarlane, 2011)?

In assuming the former for the sake of argument, Kuhn's (1970, p. 97) assertion that "there are, in principle, only three types of phenomena about which a new theory might be developed" will set the stage for a closer look at the anonymous peer reviewer's comment mentioned earlier.

"The first consists of phenomena already well explained by existing paradigms" (Kuhn, 1970, p. 97). Evidence that this type is not applicable has been provided by the profound changes between the OKM and PKM approaches (in each one of the four clusters/components as summarized in Figure 2). It also has to take account of the pressing needs and inefficiencies that are felt strongly and manifest themselves not only as being critical of higher education not being able to transform adequately (Schmitt \& Butchart, 2014), but also as e-Learning technologies failing to deliver, academic-paper-based citation and reputation systems lagging the pace, scope, and openness of online scholarship, knowledge management systems neglecting sensemaking and innovation as well as the detrimental effects caused by the digital and innovation divides (Schmitt, 2014f). Despite better ideas and forewarnings (Bush, 1945; Simon, 1971) having been widely acknowledged, they did not have the intended impact on the situations we are presently facing.

"A second class of phenomena consists of those whose nature is indicated by existing paradigms" bearing in mind that "a new theory does not have to conflict with any of its predecessors" (Kuhn, 1970, p. 97). This second type is a definite option. As has been stated, the proposed novel PKMS is not meant to be at the expense of OKM Systems, but rather as the means to foster a fruitful coevolution based on a common ground of shared KM theories and practices. This collaborative approach is also due to pragmatic reasons. Firstly, most of the world's extelligence does initially not exist in meme-based but document-centric formats, but can - as other web-related innovations have successfully demonstrated (e.g., Wikipedia, Google Books, Google Scholar) - be realigned with the assistance of self-interested user communities. Secondly, success in the digital environment depends on high rates of the diffusion and adoption of innovations; the more agents (individuals and institutions) perceive an innovation as advantageous, the more likely is their early engagement or commitment. A prior paper has adapted Mostert's Six Levels of Appreciation to fit the PKM context and describes the extent to which potential PKM stakeholders assess potential application opportunities (Mostert, 2006; Schmitt, 2014d).

The third type of phenomena recognizes "anomalies whose characteristic feature is their stubborn refusal to be assimilated to existing paradigms. This type alone gives rise to new theories. [...] In the process of being assimilated, the second must displace the first.[...] It is hard to see how new theories could arise without these destructive changes in beliefs about nature" (Kuhn, 1970, p. 97). However, Kuhn also stated "that there can be small revolutions as well as large ones, that some revolutions affect only the members of a professional subspecialty, and that for such groups even the discovery of a new and unexpected phenomenon may be revolutionary." In this latter sense, the third type is also a viable option. Evidence is based on the barriers identified which are holding back user-friendly personal KM solutions and have led to a plea for the Six Vital Provisions cited earlier (Schmitt, 2014f, 2015c). These barriers benefit service providers, but at the expense of their users, manifesting themselves in form of lost opportunities (time, money, status) or negatively impacted relationships and well-being for the knowledge workers concerned.

The critique of these business practices has not only been articulated as cited by Levy, but also, for example, by Thaul (2014, p. 77), “These entry (and exit) barriers are built on purpose. This 
way the solution suppliers want to tie their users in and not to offer them any easy possibilities to leave them - at least not without any disadvantages or problems" as well as Van Kleek and O'Hara $(2014$, pp. 125, 154) who argue in favor of autonomous technical architecture of Personal Data Stores (PDSes) "that facilitate the longitudinal, decentralized and individual-centric personal collection and curation of data" in response "to the pressing problem of the autonomy of the data subject, and the asymmetry of power between the subject and large scale service providers/data consumers."

Again, the web-based innovations exemplified before have demonstrated how fast inflexible and inconsiderate business models can be made obsolete. It also shows that potentially innovative solution (for example, Mendeley, a 2008 start-up hailed by Weinberger (2012) as a microcosm of the new ecology of networked science) can simply be swallowed up by traditional publishing giants favoring restrictive practices (Dobbs, 2013). Big players, on the other hand, do have the necessary muscle to change obstinate copyright laws: In a landmark US copyright case in November 2013, a judge ruled Google's massive book scanning project as part of its plans to scan and index every text on the globe (allowing users of its search engine to find snippets of copyrighted work without author permission) is legal under fair use terms. The overall assessment concludes that "Google Books provides significant public benefits. It advances the progress of the arts and sciences, while maintaining respectful consideration for the rights of authors and other creative individuals, and without adversely impacting the rights of copyright holders. It has become an invaluable research tool that permits students, teachers, librarians, and others to more efficiently identify and locate books. It has given scholars the ability, for the first time, to conduct full-text searches of tens of millions of books. It preserves books, in particular out-of-print and old books that have been forgotten in the bowels of libraries, and it gives them new life. It facilitates access to books for print-disabled and remote or underserved populations. It generates new audiences and creates new sources of income for authors and publishers. Indeed, all society benefits" (United States District Court, 2013). The U.S. Author's Guild is appealing the decision.

So, a conclusion, regarding the type of phenomena or if Kuhn's notion of scientific revolution is applicable at all, is debatable. What ought to be deduced from the discussion is that we are potentially facing what is termed a General Purpose Technology or Disruptive Innovation. If this prediction proves right, the world will be ripe for a new version of James Brown's 'It is a Man's, Man's, Man's World' to be titled 'It is a Memes', Memes' Memes' World':

In tune with James Brown's meme/song “It's a Man's Man's Man's World” (changes made in italics): 'It is a Memes', Memes' Memes' World':

This is a meme's world; This is a meme's world; But it wouldn't be nothing, nothing; Without a mem'ry or a thought; You see memes made the cars; To take us over the road; Memes made the train; To carry the heavy load;

Memes made the electric light; To take us out of the dark; Memes made the boat for the water; Like they made the ark;

This is a meme's, meme's, meme's world; But it wouldn't be nothing, nothing; Without a mem 'ry or a thought;

Memes thrived along a little bit on bigger brains; And on talk ' $n$ prose;

Memes make folks happy; 'Cause memes make them smart;

And after memes tried everything; Everything they can; Memes made P. K. M. S.; To keep thriving further on;

This is a meme's world; But it wouldn't be nothing, nothing; Not one little thing; Without a mem 'ry or a thought;

It's lost in the senselessness; It's lost in stupidness; It's lost. 


\section{Glossary}

Creative Class: In addition to the traditional division of the workforce into an agricultural, working, and service class, Richard Florida introduced the concept of the Creative Class as a rising and driving force of economic development. Estimated to be one third of the workforce in the United States, their economic function is to create new ideas, new technology, or new creative contents as well as to engage in complex problem solving that involves a great deal of independent judgment and requires high levels of education or human capital (Florida, 2012).

Disruptive Innovation: A disruptive innovation is an innovation that helps create a new market and value network, and eventually disrupts an existing market and value network (over a few years or decades), displacing an earlier technology. The term is used in business and technology literature to describe innovations that improve a product or service in ways that the market does not expect, typically first by designing for a different set of consumers in a new market and later by lowering prices in the existing market" ("Disruptive innovation," 2014).

General-purpose technologies (GPTs): GPTs "are technologies that can affect an entire economy (usually at a national or global level). GPTs have the potential to drastically alter societies through their impact on pre-existing economic and social structures. Examples include the steam engine, railroad, interchangeable parts, electricity, electronics, material handling, mechanization, control theory (automation), the automobile, the computer, and the Internet" ("General purpose technology," 2014).

Hosts: A host must be able to possess at least the potential capacity to elaborate on a meme and to perform those cognitive tasks connected to the meme that we normally refer to as "understanding" (G. Grant, 1990).

ICT4D: As pointed out by Johri and Pal (2012), current ICT for Development (ICT4D) efforts "are [unfortunately] primarily framed in the theory and practice of development and empowerment", signifying "a disproportionate emphasis [...] on fulfilling basic needs of users in lowresource environments without adequate attention to user-motivated concerns which would enrich their lives rather than merely provide access and satisfy basic needs." To overcome this gap, they advance a design framework, named capable and convivial design (CCD) and propose targeting four primary design characteristics, "if ICTD is to satisfy its purported goal of making a real difference in the lives of its intended beneficiaries - those that are significantly disadvantaged in terms of resources as well as opportunities": 1. Access to Artifacts (accessibility easiness), 2. Ability for Self-Expression (expressive creativity), including the ability to use personal energy creatively and to personalize the environment, 3. Ability to interact and form Relationships with other People (relational interactivity), and 4. Opportunity to enrich the Environment (ecological reciprocity).

Ideosphere: Memetics is the study of ideas and concepts viewed as 'living' organisms, capable of reproduction and evolution in an 'Ideosphere' (Sandberg, 2000) which forms an "invisible but intelligible, metaphysical sphere of ideas and ideation" where we engage in the creation of our world. "This means that the substance of the world is idea, which forms, reforms, and transforms itself via the conversations of humankind, synergetically organizing itself as an evolutionary, multidimensional network [with technology just an artefact of idea]. The problem, however, is that the majority of humanity remains the consumer of ideas without being the producer". Hence, Kimura (2005) calls for an ideospheric transformation set off by a synergetic phenomenon that emerges "when individuals in sufficient numbers become authentic, independent thinkers, that is, originators of ideas, producers of dialogues, and contributors to the network of conversations that comprises the world" (Schmitt, 2014e). 
Information Space: Boisot's 'Information Space' or 'I-Space' model entails a three-dimensional matrix formed by the axes of codification, abstraction, and diffusion. The original model depicts the dynamic flow of knowledge assets following a 'Social Learning Cycle' through six phases: scanning, codification, abstraction, diffusion, absorption, and impacting (Boisot, 2004).

Knowledge Workers: Gurteen places - rather than an individual's type of work (as in Florida's Creative Class) - the virtue of responsibility at the center of his reflections: "Knowledge workers are those people who have taken responsibility for their work lives. They continually strive to understand the world about them and modify their work practices and behaviors to better meet their personal and organizational objectives. No one tells them what to do. They do not take 'no' for an answer. They are self-motivated". To Gurteen's mind, they "cannot be coerced, bribed, manipulated or rewarded and no amount of money or fancy technology will 'incentivize' them to do a better job. Knowledge workers see the benefits of working differently for themselves. They are not 'wage slaves' - they take responsibility for their work and drive improvement" (Gurteen, 2006).

Meme: Memes were originally described by Dawkins (1976) as units of cultural transmission or imitation. They are (cognitive) information-structures that evolve over time through a Darwinian process of variation, selection and transmission. Able to self-replicate by utilizing mental storage in human hosts, they influence their hosts' behavior to promote further replication. From the meme's-eye view, every human is a machine for making more memes, a vehicle for propagation, an opportunity for replication and a resource to compete for. But, memes exist only virtually and have no intentions of their own; they are merely information pieces in a feedback loop with their longevity being determined by their environment (Bjarneskans et al., 1999; Blackmore, 2000; Collis, 2003; Schmitt, 2014e).

Meme Pool: To gain an advantage in competing for attention and survival, it pays to form symbiotic relationships with other memes (memeplexes) to mutually support each other's fitness and to replicate together. The full diversity of memes accessible to a culture or individual is referred to as Meme Pool (G. Grant et al., 1999).

Memex: Vannevar Bush (then President Truman's Director of Scientific Research) imagined the 'Memex', a hypothetical sort of mechanized private file/desk/library-device. It is supposed to act as an enlarged intimate supplement to one's memory, and enables an individual to store, recall, study, and share the "inherited knowledge of the ages". It facilitates the addition of personal records, communications, annotations, contributions as well as non-fading trails of one's individual interest through the maze of materials available - all easily accessible and sharable with the Memexes of acquaintances (Bush, 1945). Davies acknowledges that "PKM is a real and pressing problem", but also concludes - sixty-six years later - in 'Still building the Memex': "Yet it does not appear that Vannevar Bush's dream has yet been fully realized on a wide scale" (Davies, 2011).

Meta-Approach of Informing Science to Modeling: The meta-systems approach provides a further conceptual development from which the Informing Science framework is derived and "applies set-theory-like thinking to the analysis of systems". For Informing Science, we use three levels of abstraction: "the implemented system, plans for implementation, and the creation of plans. (The "houses" we are building are systems to inform our clients. We are creating environments that promote informing.)" (Cohen, 1999).

Open Science: Society overall benefits from an open and flawless exchange of ideas within the scholarly community. Hence, 'Open Science' is "based on the premise that scholarly information is a 'public good" and "the emphasis in e-Research on enhancing scholarship by improving access to information is an implicit endorsement" (Borgman, 2003). 
Opportunity Divides: The 'digital divide' describes "the uneven distribution of ICT across society, distinguishing between 'digerati' and 'have-nots' and thus defining 'cyber-classes'. Unequal access to ICT is determined by social and physical barriers, from never having seen a PC to absence of electricity infrastructure to power a PC. [...] Within nations the digital divide follows the lines of gender, wealth and education, race, and minority designation, whereas between countries this global digital divide follows the lines of national wealth, literacy, and democracy. [...] With the global digital divide attributed to barriers of supply (affordability of ICT for poor nations and people) and demand (low e-literacy), policies to bridge the global digital divide are designed around technology aid. The 'innovation divide' describes "the gap in technology creation [between technology innovators and non-innovators] and thus in ownership of the related intellectual property (IP). [...] Innovators create novel technologies and then benefit from both their use and the royalties of their commercialization; non-inventors are dependent on purchasing the rights of use of any such technology. [...] The closing of the global innovation divide is understood to be obviously dependent on the basic conditions of ICT access and e-literacy, but it is also addressed with several targeted policies:" fostering communities of innovation by establishing clusters of technology creation and commercialization, creation of the required infrastructural conditions, and addressing the cultural roots of technology innovation which centers on how to train or educate for entrepreneurship and creativity (Drori, 2010).

Personal Mastery: In 'The Shift', Lynda Gratton (2011) analyses the changing patterns of work and assesses the implications for professionals. It takes time and concentration to become masterful. She cites psychologist Daniel Lvitin's study of people who have achieved mastery in their role as composers, basketball players, fiction writers, ice skaters ... and master criminals. Lvitin found that, despite their very different areas of skill, they all had one thing in common, "a capacity to concentrate on developing their skill for long periods of time. In fact, he found that 10,000 hours is the common touchstone for how long it takes to achieve mastery."

Systems Thinking: "At the core of systems thinking is a concept, which clearly derives from our intuitive knowledge of organisms: the concept of a whole entity, which can adapt and survive, within limits, in a changing environment. [...] Today, systems-thinking has emerged as a metadiscipline and as a meta-language" able to be applied in many different areas, "including natural systems (the study of the wholes created by nature in physical sciences), designed systems (the study of the wholes designed and made by human beings in engineering disciplines) as well as management systems (the study of human activities in social sciences)" (Vat, 2004).

Vectors: Vectors form part of the private and shared world extelligence. A vector is anything that transports a meme between hosts without the capacity to reflect on the meme, e.g. books, spoken message, observed behavior, CD, pictures, or artefacts (G. Grant, 1990).

\section{References}

Andriessen, D. (2006). On the metaphorical nature of intellectual capital: A textual analysis. Journal of Intellectual Capital, 7(1), 93-110.

Andriessen, D. (2011). Metaphors in knowledge management. Systems Research and Behavioral Science, 28(2), 133-137.

Armour, P. G. (2000). The five orders of ignorance. Communications of the ACM 2000, 43(10), 17-20.

Bedford, D. A. D. (2013). Knowledge management education and training in academic institutions in 2012. Journal of Information \& Knowledge Management, 12(4).

Beinhocker, E. D. (2006). The origin of wealth. Harvard Business Press.

Bjarneskans, H., Grønnevik, B., \& Sandberg, A. (1999). The lifecycle of memes. Retrieved from http://www.aleph.se/Trans/Cultural/Memetics/memecycle.html 
Blackmore, S. J. (2000). The power of memes. Scientific American, 283(4), 52-61.

Boisot, M. (2004). Exploring the information space: A strategic perspective on information systems. Working Paper Series WP04-003. University of Pennsylvania.

Borgman, C. L. (2003). Personal digital libraries: Creating individual spaces for innovation. NSF Workshop on Post-Digital Libraries Initiative Directions, June 4, 2003.

Bush, V. (1945). As we may think. The Atlantic Monthly, 176(1), 101-108.

Cohen, E. (1999). Reconceptualizing information systems as a field of the transdiscipline informing science: From ugly duckling to swan. Journal of Computing and Information Technology, 7(3), 213-219.

Cohen, E. (2009). A philosophy of informing science. Informing Science: the International Journal of an Emerging Transdiscipline, 12, 1-15. Retrieved from http://inform.nu/Articles/Vol12/ISJv12p001015Cohen399.pdf

Collis, J. (2003). Introducing memetics. Retrieved from http://meme.sourceforge.net/docs/memetics.php

Davenport, T. H. (1994). Saving IT's soul: Human centered information management. Harvard Business Review, March-April, 72(2), 119-131.

Davidson, C. N. (2011, April). So last century. Times Higher Education.

Davies, S. (2011). Still building the Memex. Communications of the ACM, 53(2), 80-88.

Dawkins, R. (1976). The selfish gene. Paw Prints.

De Rosnay, J. (1979). The macroscope: A new world scientific system. Retrieved from http://pespmc1.vub.ac.be/macrbook.html

Disruptive innovation. (2014). In Wikipedia. Retrieved from http://en.wikipedia.org/wiki/Disruptive innovation

Dobbs, D. (2013, April 12). When the rebel alliance sells out. The New Yorker. Retrieved from http://www.newyorker.com/tech/elements/when-the-rebel-alliance-sells-out

Drori, G. S. (2010). Globalization and technology divides: Bifurcation of policy between the 'digital divide' and the 'innovation divide'. Sociological Inquiry, 80(1), 63-91.

Evans, P. C., \& Annunziata, M. (2012). Industrial Internet: Pushing the boundaries of minds and machines. General Electric.

Florida, R. (2012). The rise of the creative class - revisited. Basic Books.

Gill, T. G., \& Murphy, W. (2011). Task complexity and design science. In $9^{\text {th }}$ Int. Conference on Education and Information Systems, Technologies and Applications EISTA, Orlando, FL, Jul 19-22, 2011.

General purpose technology. (2014). In Wikipedia. Retrieved from http://en.wikipedia.org/wiki/General_purpose technology

Grant, G. (1990). Memetic Lexicon. Retrieved from www.aleph.se/Trans/Cultural/Memetics/meme_lex.html

Grant, G., Sandberg, A., \& McFadzean, D. (1999). Memetic lexicon. Retrieved from http://www.lucifer.com/virus/memlex.html

Grant, K. (2011). Knowledge management, an enduring but confusing fashion. Electronic Journal of Knowledge Management, 9(2), 117-31.

Gratton, L. (2011). The shift - The future of work is already here. UK: HarperCollins.

Gurteen, D. (2006). Taking responsibility. Inside Knowledge, 10(1). Retrieved from http://www.ikmagazine.com/display.asp?articleid=ae03flca-f94b-4bd5-9be9-0cb68079cb6f

Hamel, G. (2012). What matters now. San Francisco: Jossey-Bass. 
Hanson, J. D. (2013). Learning on the shop floor: The behavioural roots of organisational Knowledge. Behavioral Issues in Operations Management, 179-198. London: Springer.

Heisig, P. (2009). Harmonisation of knowledge management - Comparing $160 \mathrm{KM}$ frameworks around the globe. Journal of Knowledge Management, 13(4), 4-31.

Herzberg, F. (1987). One more time: How do you motivate employees? Harvard Business Review, September-October, 109-120.

Hughes, J. (2011). On the origin of tepees. Free Press.

Johri, A., \& Pal, J. (2012). Capable and convivial design (CCD): A framework for designing ICT for human development. Information Technology for Development, 18(1), 61-75.

Kahle, D. (2009). Designing open educational technology. In T. Iiyoshi \& M. S. Vijay Kumar (Eds.), Opening up education (pp. 27-46). MIT Press.

Kano, N., Seraku, N., Takahashi, F., \& Tsuji, S. (1984). Attractive quality and must be quality. Quality, 14(2), 39-48.

Kerwin, A. (1993, February 15). None too solid medical ignorance. Science Communication, 166-185.

Kimura, Y. G. (2005). Kosmic alignment - A principle of global unity. Kosmos Journal. Retrieved from http://www.via-visioninaction.org/via-li/articles/Kosmic Alignment.pdf

Koltko-Rivera, M. E. (2006). Rediscovering the later version of Maslow's hierarchy of needs: Selftranscendence and opportunities for theory, research, and unification. Review of General Psychology, $10(4), 302$.

Kruger, J., \& Dunning, D. (2009). Unskilled and unaware of it: How difficulties in recognizing one's own incompetence lead to inflated self-assessments. Psychology, 1, 30-46.

Kuhn, T. S. (1970). The structure of scientific revolutions (2nd ed.). University of Chicago Press.

Leavitt, H. J. (1965). Applied organizational change in industry: Structural, technological and humanistic approaches. In J. G. March (Ed.) Handbook of organizations. Chicago: Rand McNally.

Levy, P. (2011). The semantic sphere 1. Wiley.

McFarlane, D. A. (2011). Personal knowledge management (PKM): Are we really ready? Journal of Knowledge Management Practice, 12(3), 108-114.

Mitchell, B. T., \& Mitchell, R. K. (2012). Digital content reuse in dynamic settings: An organizing typology for digital content users. Proceedings of JAIS Theory Development Workshop. Sprouts: Working Papers on Information Systems, 12(18). Retrieved from http://sprouts.aisnet.org/12-18

Mostert, M. (2013). Systemic leadership learning. Knowres Publishing.

Nielsen, M. (2011). Reinventing discovery - The new era of networked science. Princeton University Press.

Nonaka, I., \& Takeuchi, H. (1995). The knowledge-creating company. Oxford University Press.

Nonaka, I., Toyama, R., \& Konno, N. (2000). SECI, Ba and leadership: A unified model of dynamic knowledge creation. Long Range Planning, 33, 5-34.

Pirolli, P. \& Card, S. (2005). The sensemaking process and leverage points for analyst technology. Proceedings of International Conference on Intelligence Analysis.

Porter, M. E. (1985). Competitive advantage: Creating and sustaining competitive performance. Free Press.

Sandberg, A. (2000) Memetics. Retrieved from http://www.aleph.se/Trans/Cultural/Memetics/

Schamanek, A. (2012). Taxonomies of the unknown. Retrieved from http://andreas.schamanek.net/w/phi/not-knowing/taxonomies of the unknown 
Schmitt, U. (2012). Knowcations - The quest for a personal knowledge management solution. $12^{\text {th }}$ International Conference on Knowledge Management and Knowledge Technologies (i-Know), Sep 05-07 2012, Graz, Austria. Copyright 2012 ACM 978-1-4503-1242-4/12/09. Graz: ACM. Retrieved from http://dl.acm.org/citation.cfm?id=2362469 or http://www.researchgate.net/publication/254464094

Schmitt, U. (2013b). Knowcations - A meme-based personal knowledge management system-in-progress. $8^{\text {th }}$ International Conference on e-Learning (ICEL), ACPI, Jun 27-28, 2013, Cape Town, South Africa. Retrieved from http://dx.doi.org/10.13140/2.1.2773.4725 (paper) http://dx.doi.org/10.13140/2.1.2016.2880 (poster)

Schmitt, U. (2013c). Innovating personal knowledge creation and exploitation. $2^{\text {nd }}$ Global Innovation and Knowledge Academy (GIKA), Jul 9-11, 2013, Valencia, Spain. Retrieved from http://dx.doi.org/10.13140/2.1.3717.6003

Schmitt, U. (2013d, July). Managing personal knowledge for the creative class economy. Poster presented at WorldFuture 2013 - Exploring the Next Horizon, Jul 19-21, 2013, Chicago, U.S.A. Retrieved from http://dx.doi.org/10.13140/2.1.1495.5201

Schmitt, U. (2013e). Managing personal knowledge to make a difference. $27^{\text {th }}$ British Academy of Management Conference (BAM), Sep 10-12, 2013, Liverpool, United Kingdom. Retrieved from http://dx.doi.org/10.13140/2.1.1227.2328

Schmitt, U. (2013f). Furnishing knowledge workers with the career tools they so badly need. International HR Development Conference (HRDC), Oct 17-18, 2013, Mauritius. Retrieved from http://dx.doi.org/10.13140/2.1.1718.7526

Schmitt, U. (2013g). Knowcations - Conceptualizing a personal second generation knowledge management system. In A. M. J. Skulimowski (Ed), Looking into the future of creativity and decision support systems. Proceedings of the $8^{\text {th }}$ Conference on Knowledge, Information and Creativity Support Systems KICSS, Nov 07-09, 2013, Krakow, Poland. Retrieved from http://dx.doi.org/10.13140/2.1.1208.8008

Schmitt, U. (2014a, January). Leveraging personal knowledge management systems for business and development. Paper presented at the $2^{\text {nd }}$ Conference Africa Academy of Management (AFAM), Jan 9-11, 2014, Gaborone, Botswana. Retrieved from http://www.researchgate.net/publication/268741050

Schmitt, U. (2014b). Personal knowledge management devices - The next co-evolutionary driver of human development?! International Conference on Education and Social Sciences (INTCESS14), Feb 03-05, 2014, Istanbul, Turkey. Retrieved from http://dx.doi.org/10.13140/2.1.4035.0401

Schmitt, U. (2014c). The role of personal knowledge management systems in making citizens highly knowledgeable. $8^{\text {th }}$ International Technology, Education and Development Conference (INTED), Mar 10-12, 2014, Valencia, Spain. Retrieved from http://dx.doi.org/10.13140/2.1.2492.7049

Schmitt, U. (2014d). How this paper has been created by leveraging a personal knowledge management system. $8^{\text {th }}$ International Conference on Higher Education (ICHE), Mar 16-18, 2014, Tel Aviv, Israel. Retrieved from http://dx.doi.org/10.13140/2.1.4379.1049

Schmitt, U. (2014e). From circuits of knowledge to circuits of personal knowledge management concepts. Paper presented at the Conference on Organizational Learning, Knowledge and Capabilities (OLKC). Apr 22-24, 2014. Oslo, Norway. Retrieved from http://dx.doi.org/10.13140/2.1.3527.1360

Schmitt, U. (2014f). Overcoming the seven barriers to innovating personal knowledge management systems. International Forum on Knowledge Asset Dynamics (IFKAD), Jun 11-13, 2014, Matera, Italy. Retrieved from http://dx.doi.org/10.13140/2.1.3789.2800

Schmitt, U. (2014h). Proposing a next generation of knowledge management systems for creative collaborations in support of individuals and institutions. Proceedings of the $6^{\text {th }}$ International Joint Conference on Knowledge Discovery, Knowledge Engineering and Knowledge Management (IC3K), Oct 21-24, 2014, Rome, Italy pp. 346-353. 978-989-758-050-5. Retrieved from http://www.researchgate.net/publication/268741643 
Schmitt, U. (2014i). Concept and prototype of a 'next generation' personal knowledge management system. Prototype Demonstration at the $6^{\text {th }}$ International Joint Conference on Knowledge Discovery, Knowledge Engineering and Knowledge Management (IC3K), Oct 21-24, 2014, Rome, Italy.

Schmitt, U. (2014j). Supporting digital scholarship and individual curation based on a meme-and-cloudbased personal knowledge management concept. Presentation at the Conference of the International Journal of Arts and Sciences (IJAS), Oct 28-31, 2014, Rome, Italy. Retrieved from http://www.researchgate.net/publication/268741922

Schmitt, U. (2014k). Making sense of e-skills at the dawn of a new personal knowledge management paradigm. Proceedings of the e-Skills for Knowledge Production and Innovation Conference, November 17-21, 2014, Cape Town, South Africa, pp. 417-447. ISSN 2375-0634. Retrieved from http://dx.doi.org/10.13140/2.1.4932.6409 (abstract) or http://dx.doi.org/10.13140/2.1.4267.0404 (poster) or http://proceedings.e-skillsconference.org/2014/e-skills417-447Schmitt815.pdf (paper)

Schmitt, U. (2014l). Significance of memes for the successful formation of autonomous personal knowledge management systems. $9^{\text {th }}$ International Conference on Knowledge, Information and Creativity Support Systems (KICSS), Nov 06-08, 2014, Limassol, Cyprus, pp. 339-345. 978-9963-700-84-4. Retrieved from http://dx.doi.org/10.13140/2.1.5135.6485 . Extended Version accepted for Springer's Advances in Intelligent Systems and Computing (AISC) Series. 2194-5357. (2015).

Schmitt, U. (2014m). The significance of 'ba' for the successful formation of autonomous personal knowledge management systems. $9^{\text {th }}$ International Conference on Knowledge, Information and Creativity Support Systems (KICSS), Nov 06-08, 2014, Limassol, Cyprus, pp. 327-338. 978-9963-700-84-4. Retrieved from http://dx.doi.org/10.13140/2.1.1432.8649 . Extended Version accepted for Springer's Advances in Intelligent Systems and Computing (AISC) Series. 2194-5357. (2015).

Schmitt, U. (2015a). From ICT4D to PKM4D: Tackling opportunity divides with a 'new knowledge management generation' of decentralized personal devices. Paper presented at the $11^{\text {th }}$ International Conference on Environmental, Cultural, Economic, \& Social Sustainability, Jan 21-23, 2015, Copenhagen, Denmark. Retrieved from http://www.researchgate.net/publication/270881065

Schmitt, U. (2015b). Embracing corporate knowledge assets via autonomous personal knowledge management devices. Paper presented at the $15^{\text {th }}$ International Conference on Knowledge, Culture, and Change in Organizations, Feb 19-20, 2015, Berkeley, California, USA. Retrieved from http://www.researchgate.net/publication/273064407

Schmitt, U. (2015c). Creating and tracing knowledge assets based on creative conversations of autonomous personal knowledge management devices and shared 'world heritage site of memes' repositories. Paper presented at the $11^{\text {th }}$ International Conference on Technology, Knowledge, and Society, Feb 23-24, 2015, Berkeley, California, USA. Retrieved from http://www.researchgate.net/publication/272396928

Schmitt, U. (2015d). Knowcations - Positioning a meme and cloud-based $2^{\text {nd }}$ generation personal knowledge management system. Forthcoming July 23, 2015 In A.M.J. Skulimowski, \& J. Kacprzyk (Eds.), Knowledge, Information and Creativity Support Systems: Recent Trends, Advances and Solutions (Selected Papers from KICSS'2013 - $8^{\text {th }}$ International Conference on Knowledge, Information, and Creativity Support Systems, November 7-9, 2013, Kraków, Poland), Springer Series: Advances in Intelligent Systems and Computing (AISC), 978-3-319-19089-1. Retrieved from https://www.researchgate.net/publication/273143388

Schmitt, U. (2015e). Quo Vadis, knowledge management: A regeneration or a revolution in the making? Forthcoming in June 2015: Journal of Information \& Knowledge Management (JIKM), Special Issue on KM Models and Theories. 0219-6492. Retrieved from http://www.researchgate.net/publication/273122157

Schmitt, U., \& Butchart, B. A. H. (2014). Making personal knowledge management part and parcel of higher education programme and services portfolios. Journal of the World Universities Forum, 6(4). Retrieved from http://wuj.cgpublisher.com/product/pub.173/prod.392 or http://www.researchgate.net/publication/268686737 
Simon, H. A. (1971). Designing organizations for an information-rich world. In M. Greenberger (Ed.), Computers, communication, and the public interest. Baltimore: Johns Hopkins Press.

Stewart, I. \& Cohen, J. (1999). Figments of reality - The evolution of the curious mind. Cambridge University Press.

Thaul, W. (2014). Supporting learning by tracing personal knowledge formation. (Doctoral dissertation, Plymouth University).

UAHSC. (2012). Q-cubed programs - What is ignorance. University of Arizona Health Sciences Center. Retrieved from http://www.ignorance.medicine.arizona.edu

United States District Court - Southern District of New York. (2013). The Authors Guild Inc. against Google Inc., Case 1:05-cv-08136-DC, Document 1088, Filed 11/14/13. Retrieved from www.wired.com/images blogs/threatlevel/2013/11/chindecision.pdf

Van Kleek, M., \& O'Hara, K. (2014). The future of social is personal: The potential of the personal data store. In D. Miorandi, V. Maltese, M. Rovatsos, A. Nijholt \& J. Stewart (Eds.), Social collective intelligence: Combining the powers of humans and machines to build a smarter society (pp. 125-158). Springer. Retrieved from http://eprints.soton.ac.uk/363518/1/pds.pdf

Vat, K. H. (2004). On the idea of organization transformation: The IS/IT design challenge in systems thinking. Journal of Issues in Informing Science and Information Technology, 1, 0941-0950.

Weinberger, D. (2012). Too big to know. Basic Books.

Whittaker, S. (2011). Personal information management: From information consumption to curation. Annual Review of Information Science and Technology, 45(1), 1-62.

Wiig, K. M. (2011). The importance of personal knowledge management in the knowledge society. In D. J. Pauleen, \& G. E. Gorman (Eds), Personal knowledge management (pp. 229-262). Gower.

Will, G. F. (1997, June 15). A faster mousetrap. New York Times.

Wood, R. (1986). Task complexity: Definition of the construct. Organizational Behavior and Human Decision Processes, 37, 60-82.

\section{Biography}

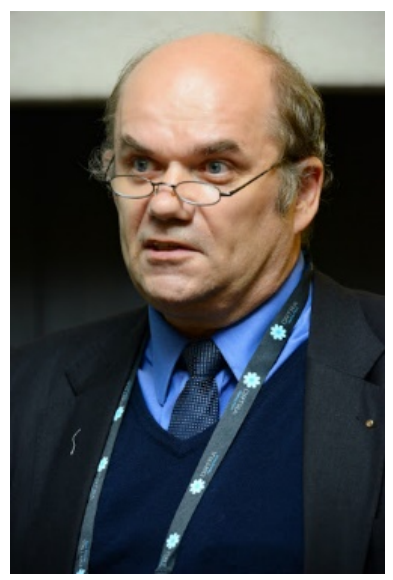

Ulrich Schmitt's professional background covers positions as IT and management consultant in London and Basle, as professor and vice president at two independent universities in Germany, as well as Vice Rector at the Polytechnic of Namibia and Dean of the Graduate School at the University of Botswana. He studied Management and Industrial Engineering at TU Berlin and Cranfield University, completed his $\mathrm{PhD}$ at Basle University, and a Science and Research Management Program at Speyer University. Currently, he is focussing on Personal Knowledge Management and is Professor Extraordinaire at the University of Stellenbosch Business School.

See web site for previous and upcoming PKM related work:

http://pkm.knowcations.net/publications http://www.researchgate.net/profile/Ulrich_Schmitt2 